\title{
Experimental investigations of bolted segmental grey cast iron lining behaviour
}

Jessica Yu a, ${ }^{*}$, Jamie Standing ${ }^{b}$, Robert Vollum ${ }^{b}$, David Potts ${ }^{b}$, John Burland ${ }^{b}$

a BuroHappold Engineering, 17 Newman Street, London W1T 1PD. Formerly Crossrail Ltd, 25 Canada Square, London E14 5LQ, UK and Faculty of Engineering, Department of Civil and Environmental Engineering, Imperial College, London SW7 2AZ, UK

b Faculty of Engineering, Department of Civil and Environmental Engineering, Imperial College, London SW7 2AZ, UK

*Corresponding author. Email address: jessicabyyu@gmail.com

\section{Abstract}

The need for the research reported in this paper was driven by the Crossrail project in London for which new tunnels were constructed close to numerous existing operational tunnels of the London Underground (LU) network.

This research component is based on experimental work conducted on half-scale grey cast iron (GCl) tunnel lining segments with chemical composition similar to the Victorian age $\mathrm{GCl}$ segments in the LU network. This paper discusses the deformation behaviour of the bolted segmental lining under the influence of factors such as overburden pressure, bolt preload and presence of grommets at small distortions. The measured behaviour of the segmental lining is compared against the calculated response of a continuous lining based on the assumption of elasticity.

The industry practice for tunnel lining assessment is to calculate the induced bending moment in the tunnel lining using an elastic continuum model, while adopting a reduced lining stiffness to take into account the presence of the joints. Case studies have recorded that both loosening and tightening of lining bolts have been used as mitigation measures to reduce the impact of new tunnel excavations on existing $\mathrm{GCl}$ tunnels.

The experimental work on the half-scale GCI lining has shown that a bolted segmental lining behaves as a continuous ring under the small distortions imposed when subjected to hoop forces relevant to the depth of burial of LU tunnels. In the presence of hoop force, joint opening was minimal and the magnitude of preload in the bolts had little impact on the behaviour of the lining. It is therefore concluded that disturbance of the bolts in existing tunnels is not recommended as a mitigation measure as in addition to being ineffective it is both time consuming and introduces the risk of damaging the tunnel lining flanges.

\section{Keywords: grey cast iron; tunnel lining behaviour}

\section{Introduction}

A major research project investigating the effect of tunnelling close to existing tunnels has been completed at Imperial College London (Standing et al., 2015). The need for the research project was driven by the Crossrail project in London for which new tunnels were constructed close to over forty existing operational tunnels. 
A common practice in industry with relation to the assessment of bending moment in tunnel linings is to use Morgan's equation (1961) to calculate the bending moment induced in the tunnel ring from a certain distortion.

Morgan (1961) set out the basis of the elastic continuum method for the analysis of a circular tunnel in elastic ground by assuming that the circular lining distorted into an ellipse and neglecting shear stresses between the tunnel extrados and the ground. The maximum bending moments occur at the tunnel axis level and at the crown and invert and are given by the following equation:

$\mathrm{M}=\frac{3 \delta \mathrm{EI}}{a^{2}}$ Equation (1)

Where $\mathrm{M}=$ maximum bending moment

$\delta=$ maximum distortion

$\mathrm{a}=$ tunnel radius

$E=$ Young's modulus of the lining

$\mathrm{I}=$ second moment of area of lining per unit width of the lining

In industry, it is common to reduce the flexural rigidity of the bolted lining ring (EI) by adopting Muir Wood's (1975) reduction formula for the second moment of area of the ring to take into account the presence of the joints:

$I_{e}=I_{J}+\left(\frac{4}{n}\right)^{2} I$ Equation (2)

Where $l_{e}=$ reduced (effective) second moment of area of lining per unit width of the lining

$I_{J}=$ second moment of area of the joint per unit width of the lining

$\mathrm{n}=$ number of segments

$I=$ second moment of area of lining per unit width of the lining

However, there is a lack of experimental data to substantiate the use of Muir Wood's (1975) reduction formula for the second moment of area for a bolted segmental tunnel lining ring to take into account the presence of the joints.

Furthermore, two case studies reported in the literature suggest that mitigating measures to reduce the impact of new tunnel excavations on existing $\mathrm{GCl}$ tunnels have included loosening bolts in one case (Moss and Bowers, 2006), and tightening bolts in another case (Kimmance et al, 1996). Therefore, the laboratory experiments performed as part of this study were also set up to investigate the effect of different bolt preloads on the behaviour of bolted segmental $\mathrm{GCl}$ rings.

This paper describes the design and set-up of the loading and monitoring components for the test ring so that the state of stress in the lining could be related to its deformed shape. The experimental lining was tested at low stress levels to minimise plastic straining of the $\mathrm{GCl}$ material. The results from the parametric studies investigating the influence of hoop force (representing overburden pressure), bolt preload and inclusion of grommets on the response of the bolted segmental ring are presented. 
As part of the research project, an extensive literature review was undertaken, focussing on cast iron, its properties and use in tunnel construction as well as other experimental work on tunnel linings. Much of this source material, whilst not directly referenced in this paper, contributed to the overall project. Notably, Copperthwaite (1906) and Hewitt and Johannesson (1922) provided a wealth of knowledge on the properties of cast iron and their historic use in the tunnelling industry and Craig and Muir Wood (1978) a good summary of earlier tunnel lining practice in the United Kingdom. Field measurements of stress and strain in cast iron and later concrete lined tunnels were reported by Rapp and Baker (1936), Skempton (1943), Cooling and Ward (1953), Sutherland (1955), Tattersall et al (1955), Ward and Chaplin (1957), Ward and Thomas (1965), Smith Osborne (1970), Thomas (1976), Attewell and El-Naga (1977), Cooley (1982), Thomas (1983), Barratt et al (1994), Davies and Bowers (1996), Nyren (1998), and Tubelines (2006). Measurements of existing tunnelling distortion due to adjacent new tunnelling were reported by Kimmance et al (1996), Cooper and Chapman (2000), Cooper (2001), Standing and Selman (2001), Cooper et al (2002 and 2003), Gue et al (2014), Alhaddad et al (2014) and Yu et al (2014).

Prior to embarking on the detailed design of the experimental set-up described here, an extensive literature search identified a small number of studies involving large-scale tests where a similar methodology was used (i.e. without soil) although none-of them adopted the combined loaddisplacement control adopted in this study. Experimental work on cast iron tunnel segments was completed by Leung (1967) and Thomas (1977), with the latter still being the key source paper on this subject. Other studies involving large-scale experimental set-ups have been made for concrete segments, either singly or forming a full or part of a ring (Mashimo et al, 2001 and 2002; Blom, 2003; Bilotta et al, 2006; Okano, 2007; Ahn, 2011; and Blazejowski, 2012). A particular focus of these studies is often to assess new materials such as fibre reinforced concrete or the segment response during erection and grouting.

\section{Experimental investigations}

\subsubsection{Overview}

The details of the half-scale ring are given in Figure 1 to 3 . The adopted size was the smallest that could be manufactured with $\mathrm{GCl}$ while maintaining true proportionality of all dimensions, particularly the skin of the segment. The linings were manufactured to have a composition that matched that of existing linings.

The experimental investigations considered the influence of joint opening on the structural response of the ring. For a continuous ring of uniform stiffness made from linear elastic material, the first order bending moments related to an imposed change in radius are independent of the hoop force. The effect of having joints, as in the case of the bolted segmental ring, is to potentially reduce ring stiffness, the reduction in magnitude being dependent on the hoop force (from the radially applied load to simulate overburden pressure) and the change in radius. One of the objectives of the laboratory experiments was to examine this relationship and the validity of applying Muir Wood's reduction formula. The bending moments derived from strain measurements in the laboratory tests were compared with the analytically obtained bending moments of a continuous lining of uniform stiffness 
under the same deformation as the test lining. The tests were repeated for different initial bolt preloads.

Circularity surveys of $45 \mathrm{~km}$ of LU running tunnels conducted from 2004 to 2005 found that the tunnels had squatted - i.e. the horizontal diameter was greater than the vertical diameter (Tube Lines, 2007). London Underground (2014) suggested that for assessment purposes it was appropriate to assume, in the absence of in-situ data, ovalisation of $1 \%$ for all tunnel lining less than 15 feet $(4.57 \mathrm{~m})$ internal diameter in cohesive ground.

In the 2D finite element (FE) analysis discussed in his PhD thesis, Avgerinos (2014) modelled the existing Central LU running tunnel at Lancaster Gate near Hyde Park. The maximum distortion of the existing tunnel was found to be $0.2 \%$ after 100 years of consolidation for the case with the lining modelled as fully permeable. When the tunnel lining was modelled as impermeable the distortion was significantly lower. This indicates that tunnel deformation as a result of ground loading alone could be significantly lower than the $1 \%$ ovalisation suggested by London Underground (2014). It is possible that for in-situ tunnels the ovalisation would have occurred during the construction of the tunnel rings, and under self-weight, prior to any ground loading being transferred to the lining.

Furthermore, Avgerinos' (2014) FE analyses showed that the action of shear stresses on the tunnel lining could control the deformed shape of the lining. However, in the laboratory set-up it was only possible to apply normal stresses to distort the ring. The effect of shear stresses was also neglected in Morgan's formulation (1961).

From a review of existing literature, it is noted that the previous maximum recorded distortion in bolted $\mathrm{GCl}$ tunnels due to new tunnel excavations is approximately $0.1 \%$ of diametral strain (Kimmance et al 1996 and Cooper, 2001). Field monitoring conducted by the Imperial College research team within one of the Central Line running tunnels also recorded, using tape extensometer measurements, a maximum change in span of $\pm 0.1 \%$ due to the Crossrail tunnel excavations. The associated joint opening was less than 5 microns (Yu et al, 2014).

Since it is difficult to ascertain exactly how the ground stresses are transferred to the tunnel lining and the magnitude of tunnel distortion resulting from ground stresses alone, it was decided to subject the $\mathrm{GCl}$ test ring to small distortions to minimise the generation of plastic strains such that the state of stress of the bolted system could be estimated from strain measurements assuming a constant elastic modulus. Also, the laboratory results could be compared with elastic solutions for a continuous ring. Additionally, of equal importance, a set of parametric experiments could be completed using the same bolted $\mathrm{GCl}$ ring. The maximum distortion applied was approximately $0.13 \%$. Section 2.2 explains why this value was selected.

\subsubsection{Scale Effects}

When the linear dimensions of an elastic structure are scaled by a factor $k$, for unchanged stress, the applied forces are changed by a factor $\mathrm{k}^{2}$, applied moments are changed by a factor $\mathrm{k}^{3}$ and deflections are changed by a factor $\mathrm{k}$. 
In the load control tests, the half-scale model ring was subjected to the same pressure (i.e. overburden) as assumed to be experienced by the real tunnel. Therefore, the strains and stresses are identical in the model and the real tunnel. Similarly, in strain control tests where the aim is to achieve a prescribed diametric distortion, the strains and stresses in the model and real tunnel would be identical.

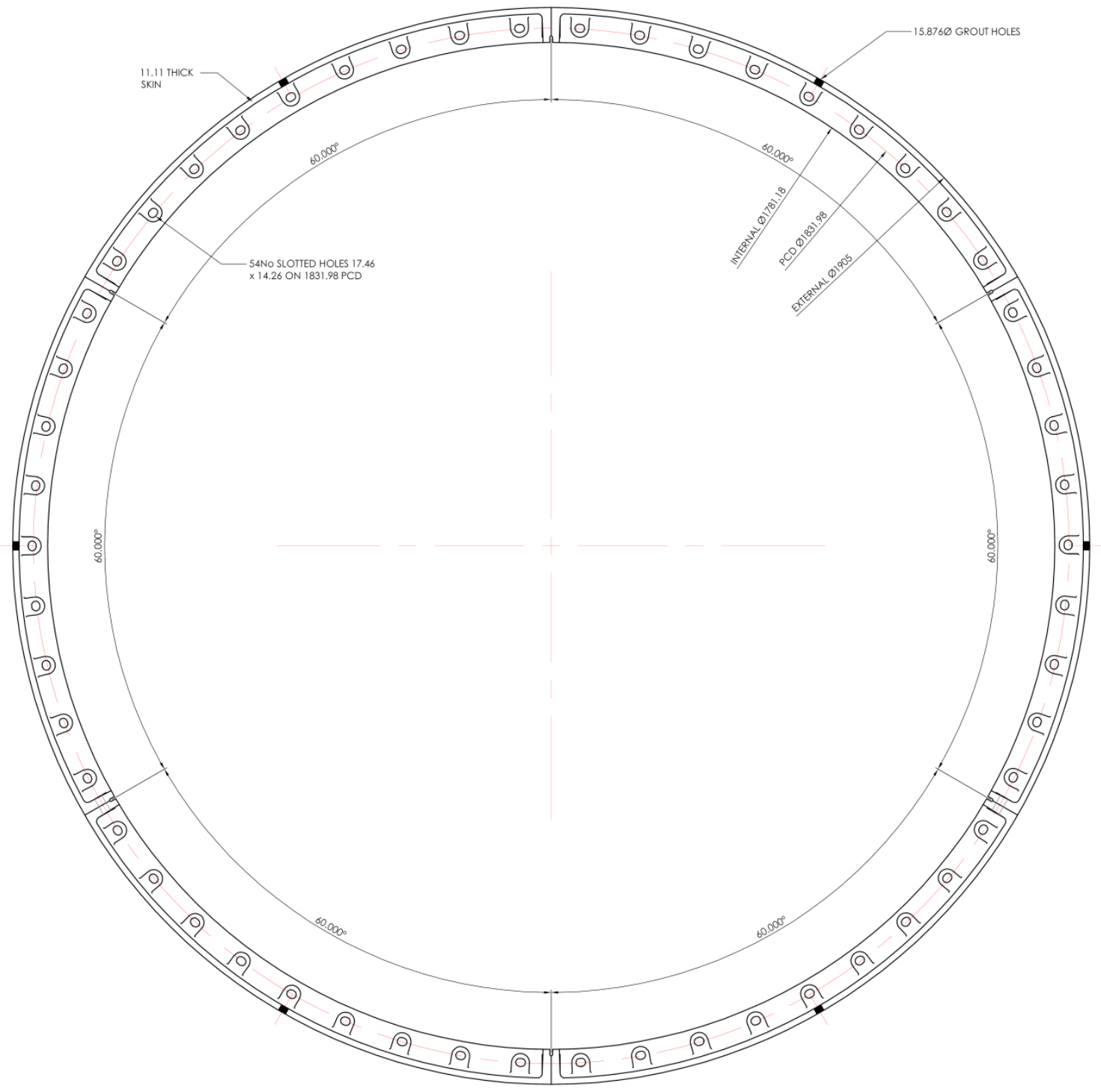

Figure 1. Half-scale GCI ring cross section. All dimensions in mm unless otherwise stated. (Underground Professional Services, 2009) 


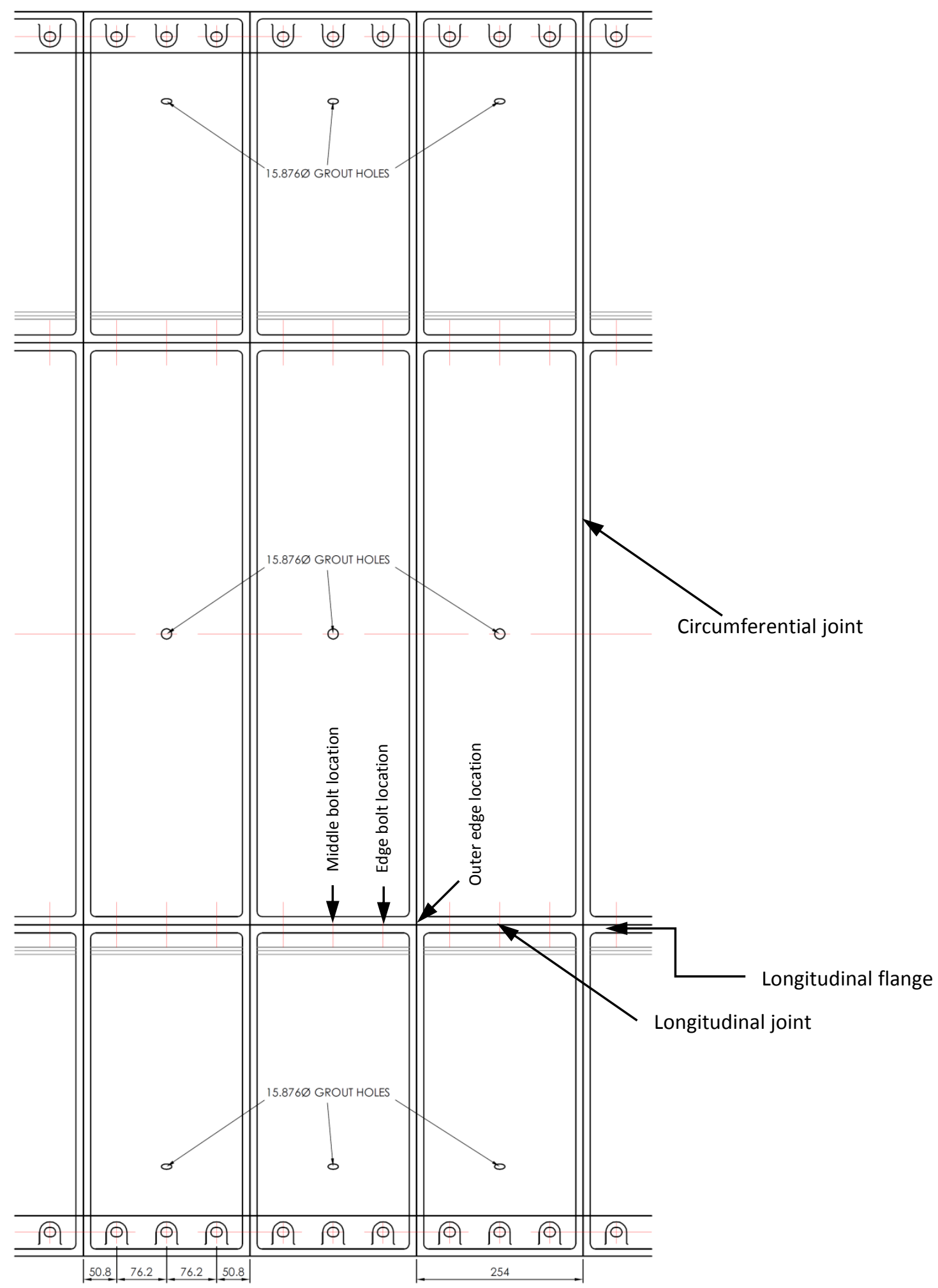

Figure 2. Half-scale GCI ring internal elevation. All dimensions in mm unless otherwise stated. (Underground Professional Services, 2009) 

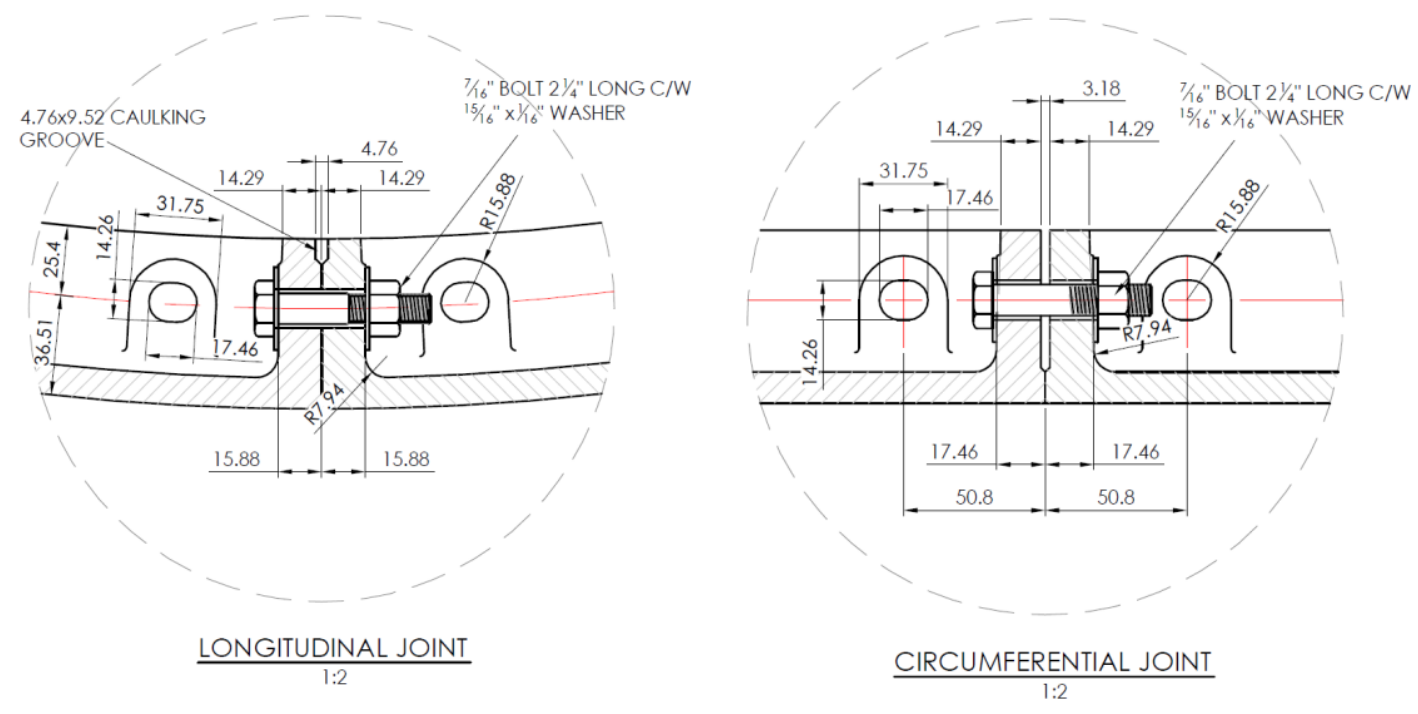

Figure 3. Longitudinal joint and circumferential joint at half-scale. All dimensions in mm unless otherwise stated. (Underground Professional Services, 2009)

\subsection{Material composition and testing}

\subsubsection{Chemical composition of experimental GCl segments}

The chemical composition of the Victorian-age GCI linings for LU tunnels was obtained from LU archive reports. The chemical composition for $\mathrm{GCl}$ as determined by Fallon (1998) was used as the basis for the mix used to cast the model segments in order to replicate the properties of the Victorian $\mathrm{GCl}$ linings in the LU network as closely as possible. The final chemical composition of the experimental $\mathrm{GCl}$ segments is given in Table 1 .

\begin{tabular}{|l|l|l|l|}
\hline Main Component (\%) & $\begin{array}{l}\text { Test results reported } \\
\text { by Fallon (1998) for } \\
\text { six GCI segments } \\
\text { dated from 1900 to } \\
1925\end{array}$ & $\begin{array}{l}\text { Test results reported by } \\
\text { Tube Lines (2008) for LU } \\
\text { Jubilee/Northern/Piccadilly } \\
\text { lines segments dated from } \\
1890 \text { to 1986 }\end{array}$ & $\begin{array}{l}\text { Test results of half-scale } \\
\text { GCI mix by Russell Ductile } \\
\text { Castings for Imperial } \\
\text { College (2010) }\end{array}$ \\
\hline Carbon & $3.12-3.54$ & 3.3 & 3.5 \\
\hline Silicon & $1.65-3.08$ & 2.3 & 2.2 \\
\hline Manganese & $0.29-1.34$ & 0.4 & 0.55 \\
\hline Sulphur & $0.05-0.13$ & 0.1 & 0.06 \\
\hline Phosphorus & $1.07-1.59$ & 1.4 & 0.88 \\
\hline CE $^{1}$ & $4.47-4.66$ & 4.5 & 4.5 \\
\hline $\begin{array}{l}\text { Average Ultimate Tensile } \\
\text { Strength }\end{array}$ & $142-175$ & 155 (pre-1928 specimens) & See Section 2.2 .2 \\
\hline $\begin{array}{l}\text { Average tensile strain at } \\
\text { failure (\%) }\end{array}$ & & 0.46 (post-1928 specimen) & \\
\hline
\end{tabular}

Table 1. Chemical composition of GCI.

Notes:

1. CarbonEquivalent, $C E=$ TotalCarbon $\%+\frac{\text { Silicon } \%+\text { Phosphorus } \%}{3}$.

2. For comparison, the ultimate tensile strength for grade $10 \mathrm{GCl}$ is $150 \mathrm{MPa}$ (Gilbert, 1977) 


\subsubsection{Mechanical properties of GCI}

During the casting of the half-scale GCl segments, bars were separately cast from the same mix for tensile testing. Seven $20 \mathrm{~mm}$ diameter specimens were machined according to BS EN 1561:1997 and tested with reference to BS EN ISO 6892-1:2009. One specimen was damaged because the clamping pressure on the jaws of the tensile test rig was too high. Of the remaining six specimens, one was tested as a conventional monotonic tensile test (GCl_1 in Figure 4), while five were loaded and unloaded several times before reaching failure. The stress at failure ranged from $128 \mathrm{MPa}$ to 152 MPa. The total strain at failure ranged from $0.57 \%$ to $1.00 \%$.

A linear variable differential transformer (LVDT) was attached to the $\mathrm{GCl}$ specimen to measure the local extension for the calculation of local axial strain. In the unload-reload tests, successively increasing strains were applied to the specimen, after each step returning to zero stress. By returning to zero stress, the permanent elongation associated with the preceding stress could be measured and used to calculate the magnitude of plastic strain. The elastic strain was estimated as the difference between the total applied strain and the calculated plastic strain. The calculated strains are presented in Figure 5. Up to a stress of $60 \mathrm{MPa}$, which was approximately $40 \%$ to $45 \%$ of the ultimate tensile strength of the specimens tested, the total strain was less than $0.1 \%$, and the plastic strain was below $0.02 \%$.

The parameters given in Table 2 were selected to be used in the planning of the laboratory experiments and in the subsequent analysis of results.

The ultimate tensile strength was selected based on the lower limit of the tensile test results from the $\mathrm{GCl}$ specimens. In the planning of the experiments, the tensile stress in the extreme fibre of the $\mathrm{GCl}$ segments was limited to $40 \%$ of the ultimate strength because the stress-strain response was almost linear up to that point and negligible plastic strains were generated. The ultimate compressive strength of the $\mathrm{GCl}$ was not tested, and was taken to be four times the ultimate tensile strength based on a literature review (Angus, 1976).

The experimental data showed that for strains less than $0.1 \%$, both the tangent and secant moduli were below $100 \mathrm{GPa}$. This value was selected for subsequent calculations to provide conservative estimates of stress from the measured strains. The Poisson's ratio was taken from the literature (Angus, 1976). 


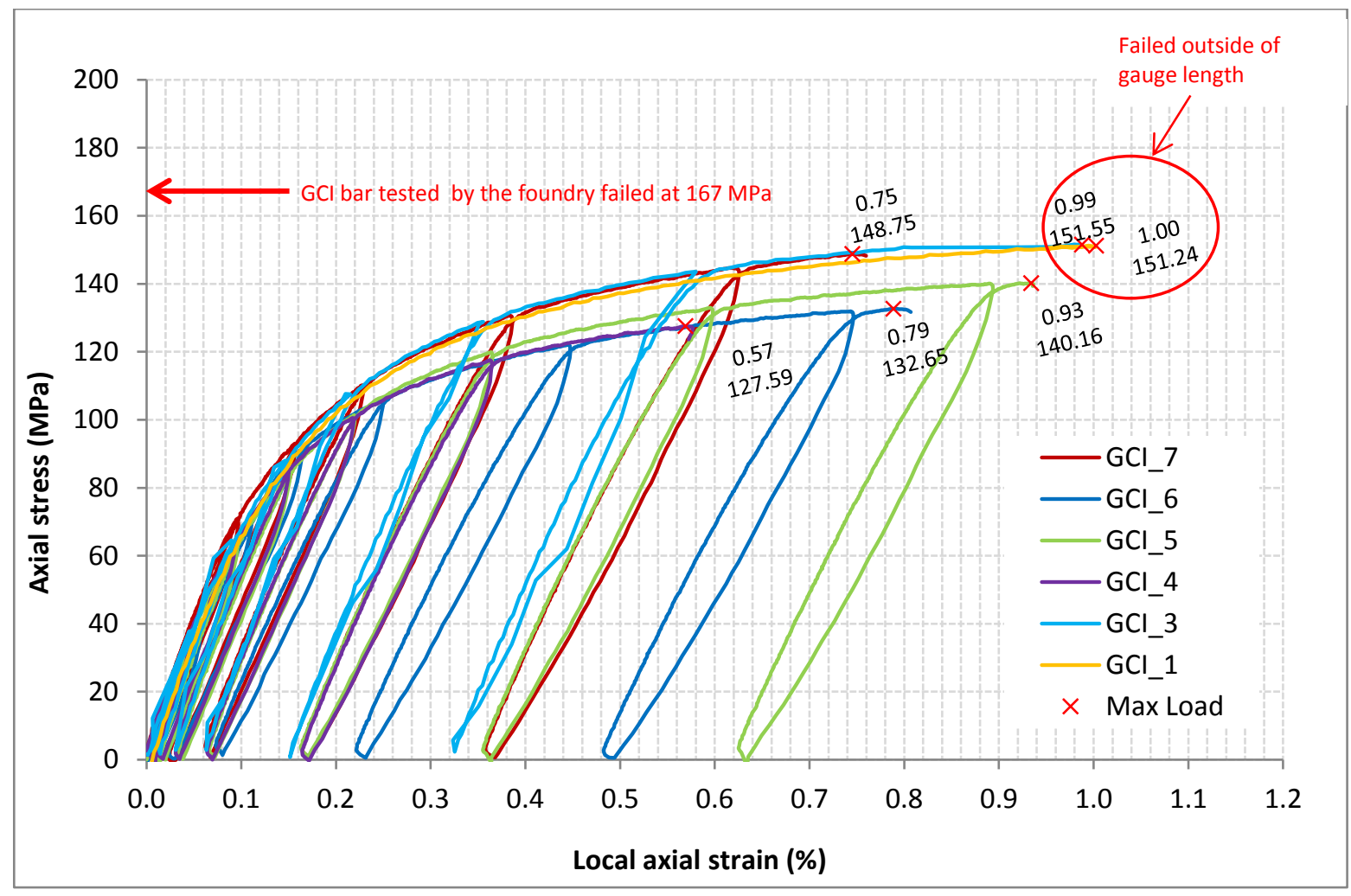

Figure 4. Stress-strain curves for 20 mm diameter GCI specimens

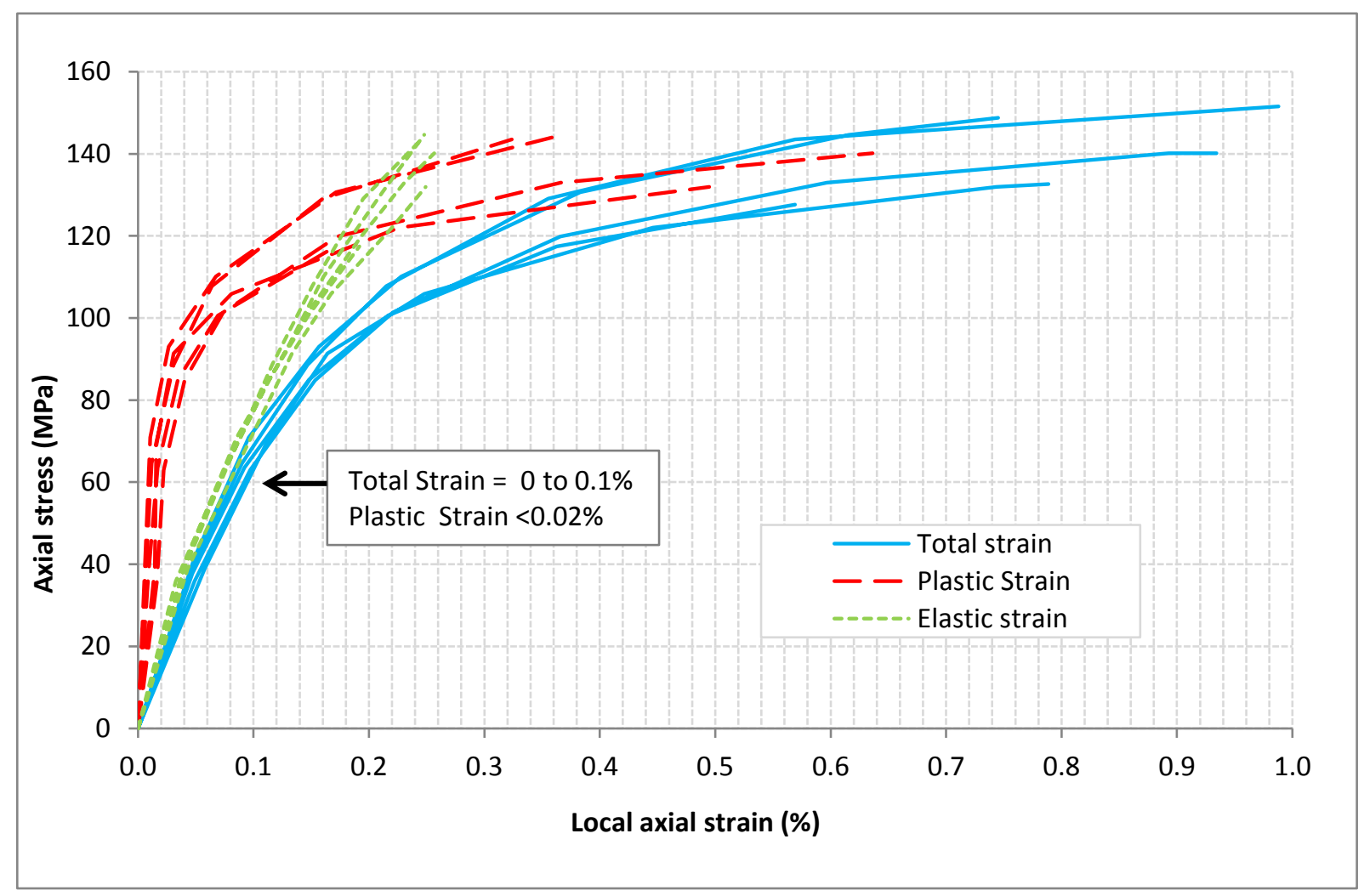

Figure 5. Total strain, plastic strain and elastic strain for the 20mm diameter GCI test specimens. 


\begin{tabular}{|l|l|}
\hline Parameter & Design value \\
\hline Ultimate tensile strength $(\mathrm{MPa})$ & 120 \\
\hline Ultimate compressive strength $(\mathrm{MPa})$ & 480 \\
\hline Elastic modulus in tension and compression $(\mathrm{GPa})$ & 100 \\
\hline Poisson's Ratio & 0.26 \\
\hline
\end{tabular}

Table 2. GCI properties for use in conjunction with laboratory experiments.

\subsubsection{Mechanical properties of wrought iron bolts}

Tube Lines (2008) tested a large number of wrought iron bolts removed from tunnel linings from sections of the Northern, Piccadilly and Jubilee LU lines. These were tested according to BS EN 10002-1:2000.

It was not possible to manufacture wrought iron bolts for the purpose of this research, so grade 4.6 mild steel bolts were used instead. Table 3 shows that the properties of grade 4.6 mild steel bolts from BS EN 1993-1-8:2005 are comparable to those of the wrought iron bolts tested by Tube Lines (2008).

\begin{tabular}{|l|l|l|}
\hline & Grade 4.6 mild steel & Wrought iron \\
\hline Tensile strength $(\mathrm{MPa})$ & 400 & 369 \\
\hline Elongation at fracture $(\mathrm{m} \varepsilon)$ & 220 & 150 to over 250 \\
\hline Yield strength $(\mathrm{MPa})$ & 240 & 239 \\
\hline Pre-yield modulus $(\mathrm{GPa})$ & 210 & 270 \\
\hline
\end{tabular}

Table 3. Properties of Grade 4.6 bolt and wrought iron bolt

\subsubsection{Use of grommets}

It was not possible to recover grommets from the LU tunnels and test for their properties. Instead, specially fabricated modern-day gel grommets were used which were manufactured from jute yarn impregnated with a waterproof gel.

\subsection{Full ring tests}

\subsubsection{Design of test rig components}

The concept for the full ring set-up was initially tested using a small-scale model comprising six segmental elements (forming a $100-\mathrm{mm}$ diameter ring) loaded by displacement control with loads applied via a reaction ring (Standing and Lau, 2016). Having proven the concept at small scale, the development of the half-scale model could then proceed with much greater confidence. The laboratory tests on the half-scale model were performed on a single test ring comprising of six $\mathrm{GCl}$ segments bolted together. The ring was supported on ball bearings, with its radial plane horizontal, to minimise friction between the ring and the floor and to eliminate self-weight effects. It was surrounded by a 3.0 $\mathrm{m}$ internal diameter reaction ring fabricated from a $254 \times 254 \times 107$ universal column section of grade S235 steel (see Figure 6 and Figure 7). The reaction ring was conservatively designed to resist the most severe loading that could be applied to the $\mathrm{GCl}$ test ring. 


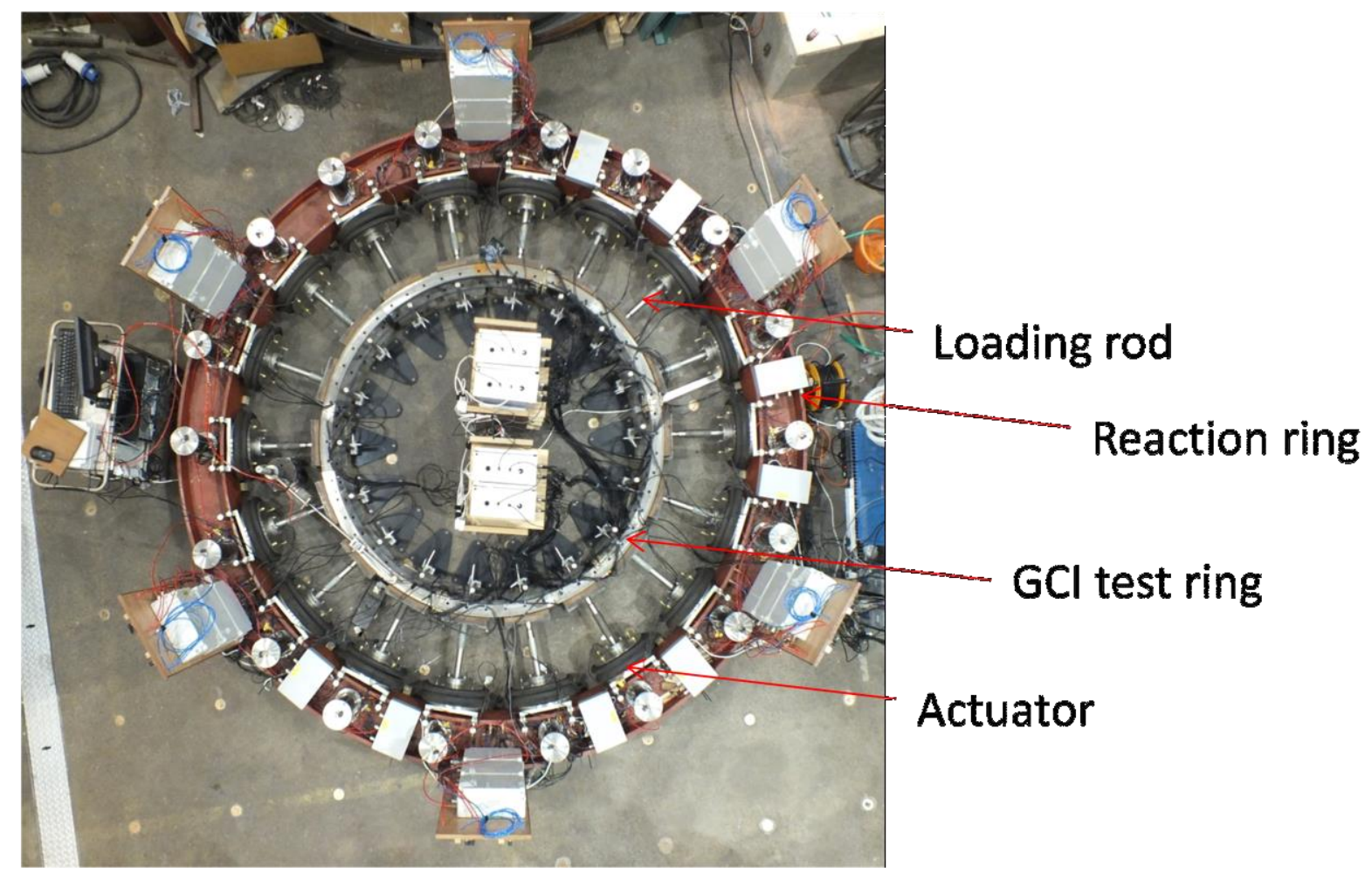

Figure 6. An annotated photo of the test setup.

Radial loading of the ring was via computer-controlled actuators installed between the reaction ring and extrados of the test lining. The advantages of this approach are as follows.

- Removal of uncertainty associated with how well stresses applied to boundaries in small-/mediumscale models replicate conditions at prototype scale when the stresses are applied using soil. Much depends on the soil type, method of placement, homogeneity, consolidation, applied boundary stresses to name a few.

- Using the approach described allows the conditions within the ring for different deformed shapes to be investigated clearly without ambiguity.

- The tests could be performed relatively quickly compared with experiments involving soil.

A drawing of the experimental setup is given in Figure 7. 


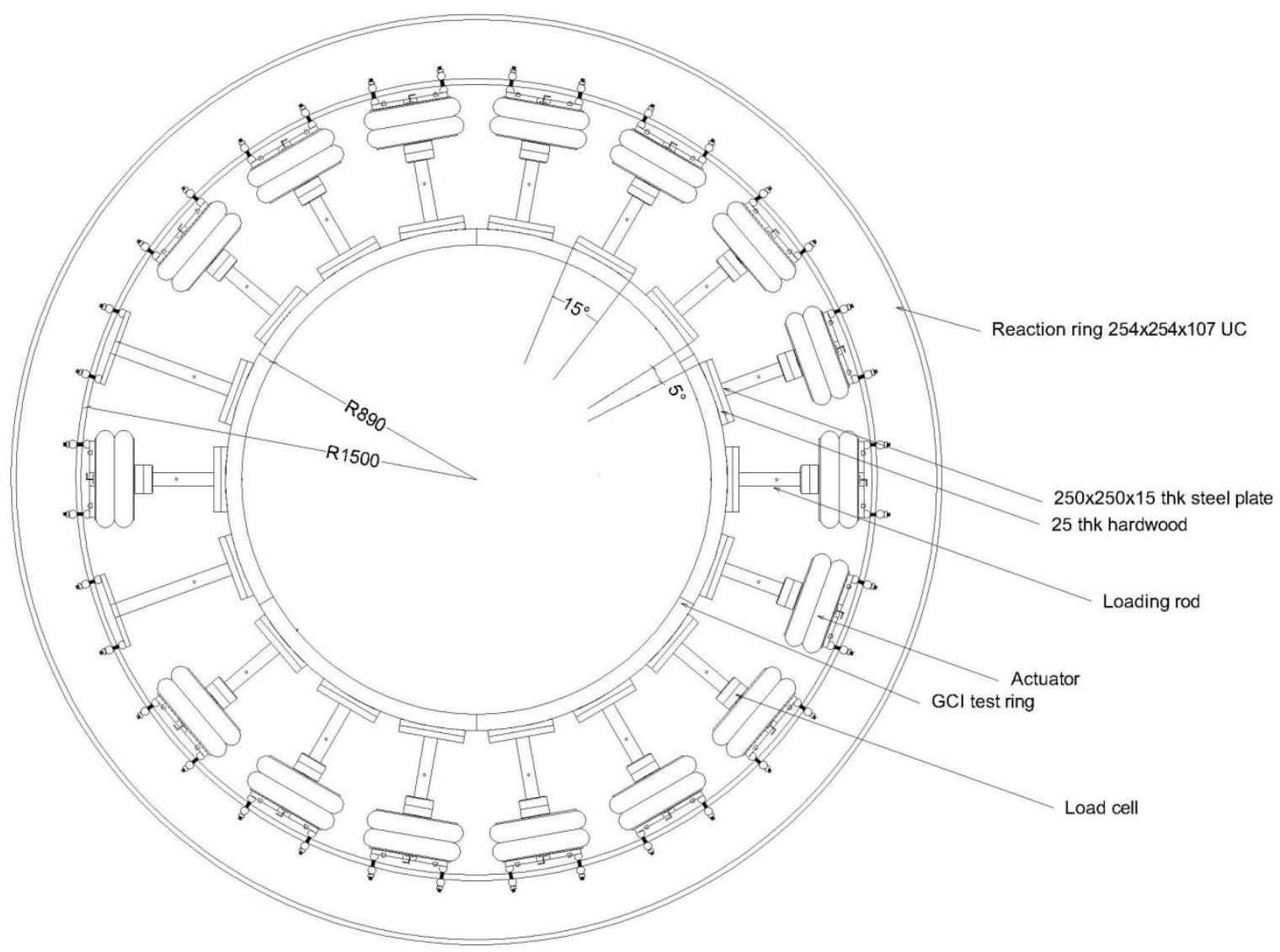

Figure 7. Drawing of test setup. All dimensions in mm unless otherwise stated.

Sixteen 14.5" diameter stainless steel air bellows were used as actuators. They were positioned onto the reaction ring at $20^{\circ}$ spacings to simulate a distributed load. Spreader pads transferred the load from the actuator to the extrados of the test segment. The bellows allowed rotational movement but the loading rods were locked into position at the connection with the spreader pads. Each spreader pad consisted of a mild steel plate attached to a piece of hardwood machined to have the same external radius as the test ring. A layer of butyl was glued onto the machined hardwood surface to ensure full contact between the spreader pad and the test ring even as the test ring was distorted.

At two locations around the ring, the actuators were replaced with reaction rods fitted with load cells. This was done to prevent rigid-body motion of the test ring. Diametrically opposite the two reaction rods, a tangential restraining member was fitted to the test ring to increase the ring stability. It allowed radial movements relative to the centre but prevented ring rotation.

\subsubsection{Instrumentation}

The force applied to each spreader pad was monitored using load cells with up to $100 \mathrm{kN}$ capacity.

Around the intrados of the $\mathrm{GCl}$ ring, displacement transducers were set up radially in line with each actuator to monitor segment deformations. The joint openings at the longitudinal joint locations (refer to Figure 2) were monitored using LVDT transducers attached onto the $\mathrm{GCl}$ ring intrados and 
extrados. The LVDTs were aligned with the middle bolt, the edge bolt and the outer edge (see Figure 2).

Forces in the bolts connecting the segments were measured using instrumented bolts. Each instrumented bolt had two small sections of the unthreaded portion planed off and two strain gauges were attached to each planed surface to form a four-arm Wheatstone bridge as shown in Figure 8. Stresses and bending moments within the segments themselves were determined from conventional strain gauge measurements at strategic locations around the segment (see Figure 9 and 10). Electrical resistance $350 \Omega$ tee rosette type strain gauges were used.

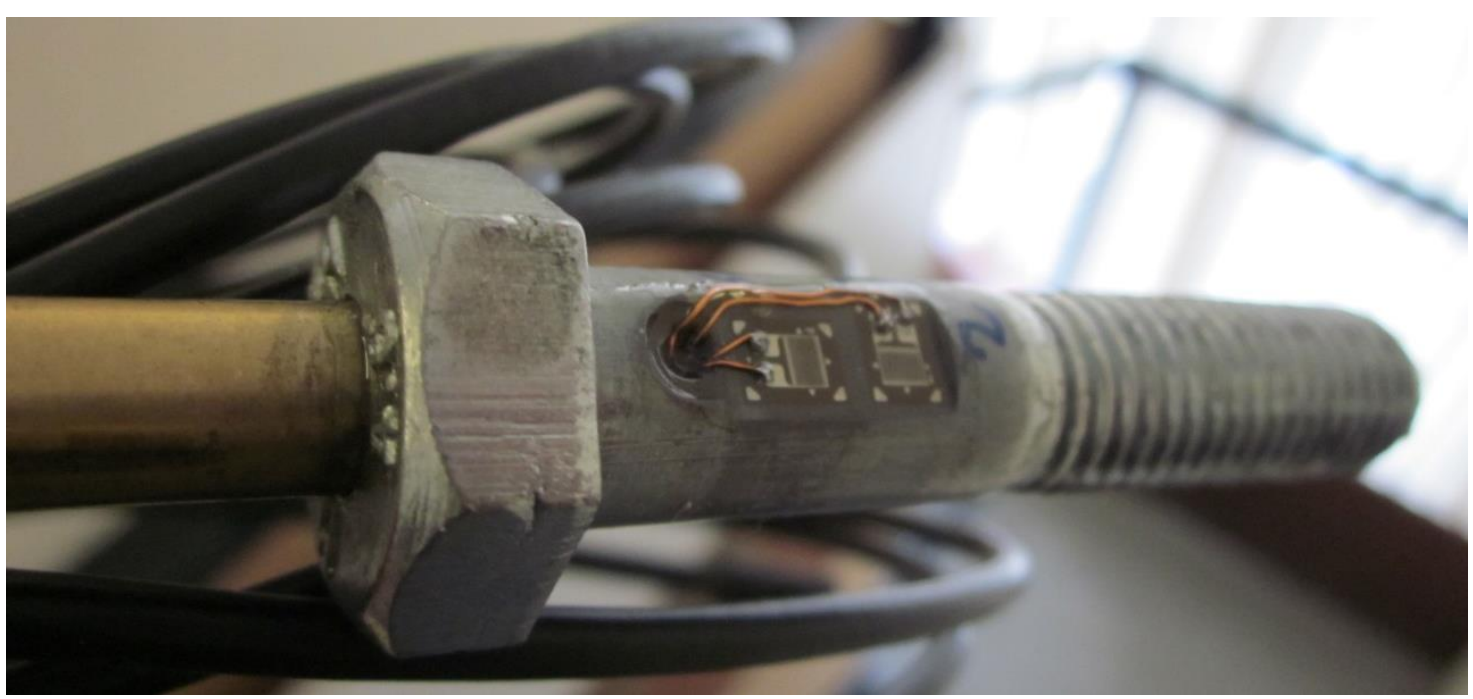

Figure 8. Instrumented bolt. 


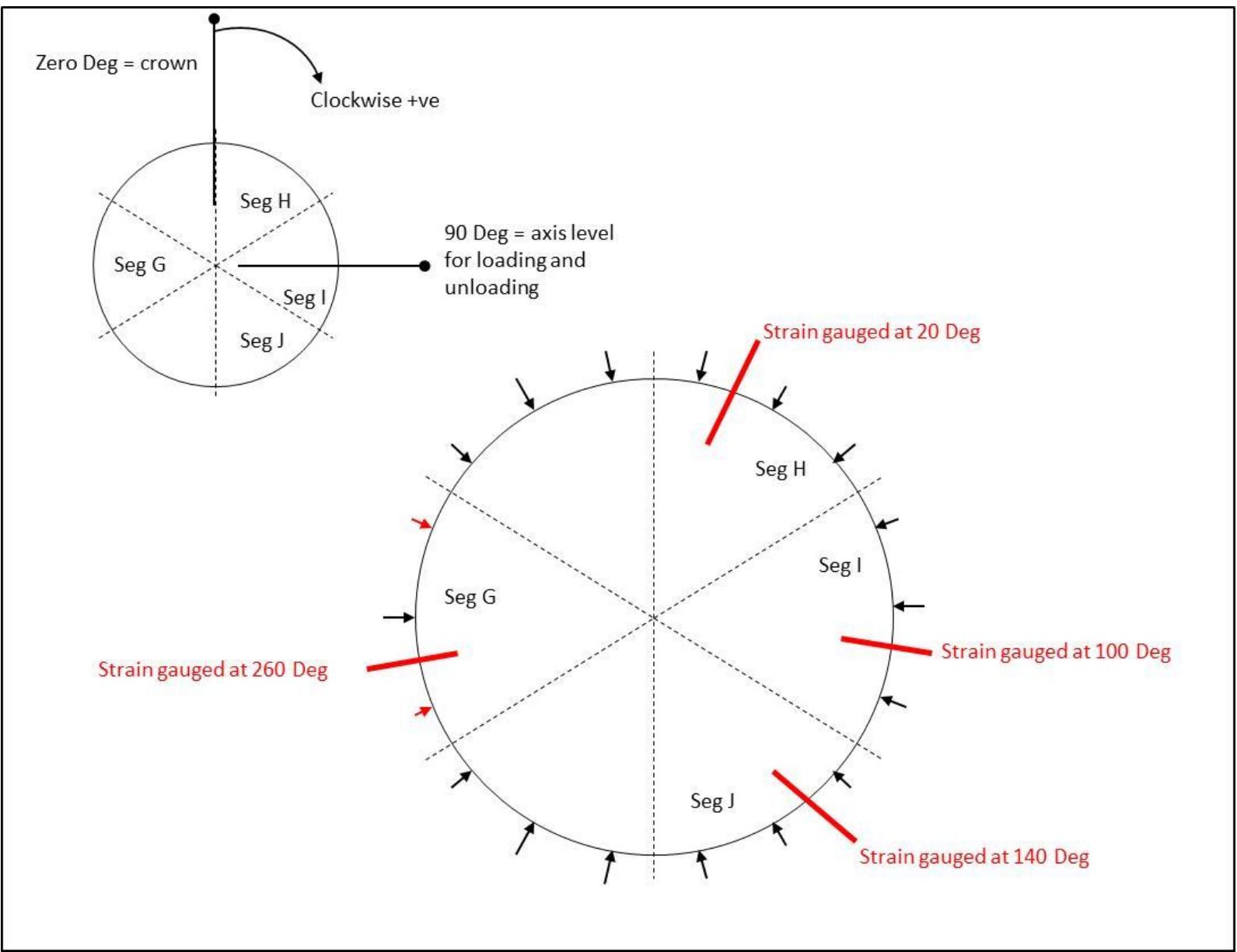

Figure 9. Sign convention and strain gauge locations for test ring.

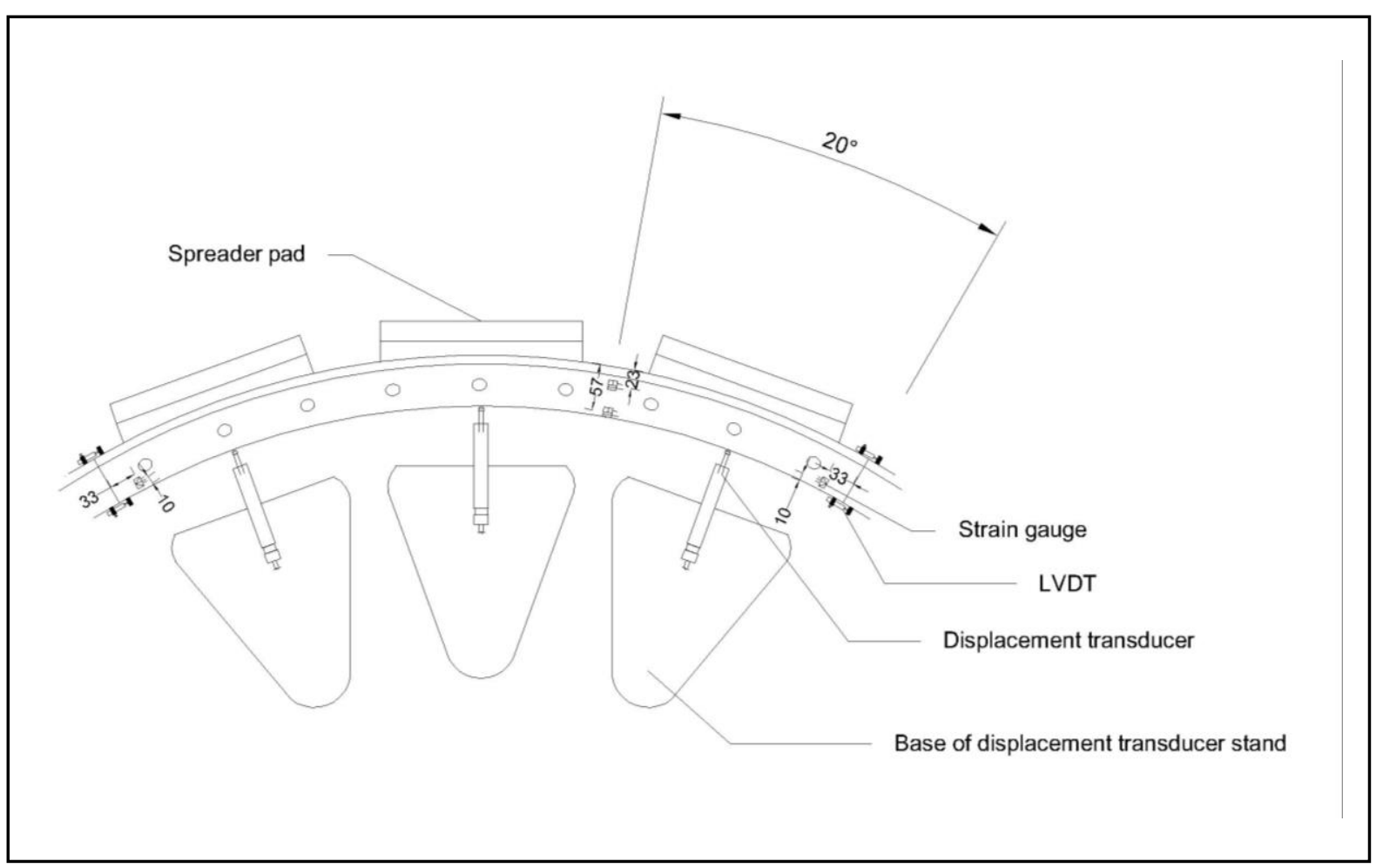

Figure 10. Strain gauge locations on Segment I. 


\subsubsection{Loading procedure}

The $\mathrm{GCl}$ test ring was loaded in two stages. Stage One was used to bring the cast iron ring under different hoop loads to represent different overburden pressures. In Stage Two the cast iron ring was subjected to distortion.

Stage One - normal loads were gradually built up using the sixteen actuators to bring the test ring under compressive hoop force with negligible bending moment induced in the test ring. Different magnitudes of normal loads were selected for Stage One to investigate the effect of varying hoop force and hence overburden pressure on the behaviour of the bolted segmental ring. The majority of the $\mathrm{GCl}$ tunnels in the LU network lie between $20 \mathrm{~m}$ and $30 \mathrm{~m}$ below ground level.

Stage Two - the load in the actuator at axis level was adjusted to achieve the prescribed displacement (Figure 9). The normal loads in the other actuators away from the axis were controlled to remain unchanged after Stage One. The bending moment in the test ring was estimated using the strain measurements at four sections around the test ring assuming a constant modulus of $100 \mathrm{GPa}$ (Figure 9).

When Stage One was reached, a scan of all the instrumentation was taken for 2 to 3 minutes and an average was computed. Once Stage Two was reached, another scan of all the instrumentation was taken. Each test was repeated three times to assess the consistency of results. The bolt preload magnitudes used in the experiments were $5 \mathrm{kN}, 7.5 \mathrm{kN}, 10 \mathrm{kN}$ and $5 \mathrm{kN}$ with grommets.

\subsubsection{Applied distortion}

Before carrying out the tests, the bending moment capacities of the $\mathrm{GCl}$ segments and the joints were estimated. The bending capacity of the half-size segment was estimated based on the section geometry. The bending moment capacity of the longitudinal joint (see Figure 2) at zero hoop force was estimated based on the flexural capacity of the longitudinal flange (see Figure 2) assuming failure when the tensile stress at the extreme fibre reached $120 \mathrm{MPa}$. Calculations outlining how the bending moment capacity of the joint was estimated are provided in Appendix A.

The bending moment capacities of the $\mathrm{GCl}$ segments and the segment joints increased as the hoop force increased. At the joint, the additional moment capacity was afforded by the hoop force in compression, $\mathrm{N}$, applied at maximum eccentricity, e, from the centroidal axis of the segment to the extreme compression fibre. Table 4 shows the estimated moment capacity under different depths of overburden pressure. Linear elasticity was assumed in all the calculations. 


\begin{tabular}{|c|c|c|c|c|c|c|c|c|}
\hline $\begin{array}{l}\text { Depth below } \\
\text { ground }\end{array}$ & $\begin{array}{l}\text { Load per } \\
\text { jack, P }\end{array}$ & $\begin{array}{l}\text { Hoop } \\
\text { force, } \\
\mathrm{N}\end{array}$ & \multicolumn{2}{|c|}{$\begin{array}{l}\text { Moment } \\
\text { capacity from } \\
\text { hoop force, } \mathrm{Ne}\end{array}$} & \multicolumn{2}{|c|}{$\begin{array}{l}\text { Total moment capacity } \\
\text { at the joint, } \mathrm{BM}_{\mathrm{J}}+\mathrm{Ne}\end{array}$} & \multicolumn{2}{|c|}{$\begin{array}{l}\text { Moment capacity of } \\
\text { segment }\end{array}$} \\
\hline \multirow[t]{2}{*}{$\mathrm{m}$} & $\mathrm{kN}$ & $\mathrm{kN}$ & $\mathrm{kNm}$ & & $\mathrm{kNm}$ & & $\mathrm{kNm}$ & \\
\hline & & & $+\mathrm{ve}$ & -ve & $+\mathrm{ve}$ & -ve & $+\mathrm{ve}$ & -ve \\
\hline 0 & 0 & 0.0 & 0.0 & 0.0 & 1.12 & 0.72 & 3.45 & 9.54 \\
\hline 2 & 3.4 & 9.7 & 0.16 & 0.35 & 1.28 & 1.07 & 3.51 & 9.72 \\
\hline 6 & 10 & 29.0 & 0.48 & 1.05 & 1.60 & 1.77 & 3.64 & 10.08 \\
\hline 12 & 20 & 58.1 & 0.96 & 2.09 & 2.08 & 2.81 & 3.84 & 10.61 \\
\hline 24 & 40 & 116.1 & 1.91 & 4.18 & 3.03 & 4.90 & 4.22 & 11.68 \\
\hline
\end{tabular}

Table 4. Estimated BM capacity for joint and segment.

Figure 11 compares the estimated bending capacities of the segment and the joint at different depths. It shows the variations in bending capacities as the hoop force increased with overburden depth. A depth range of $20 \mathrm{~m}$ to $30 \mathrm{~m}$ was the most relevant to the bolted segmental $\mathrm{GCl}$ tunnels in the LU network. In this depth range, the estimated joint bending capacity is lower than the segment bending capacity. The capacities were calculated for positive bending (akin to straightening the segment) and negative bending (akin to increasing the curvature of the segment).

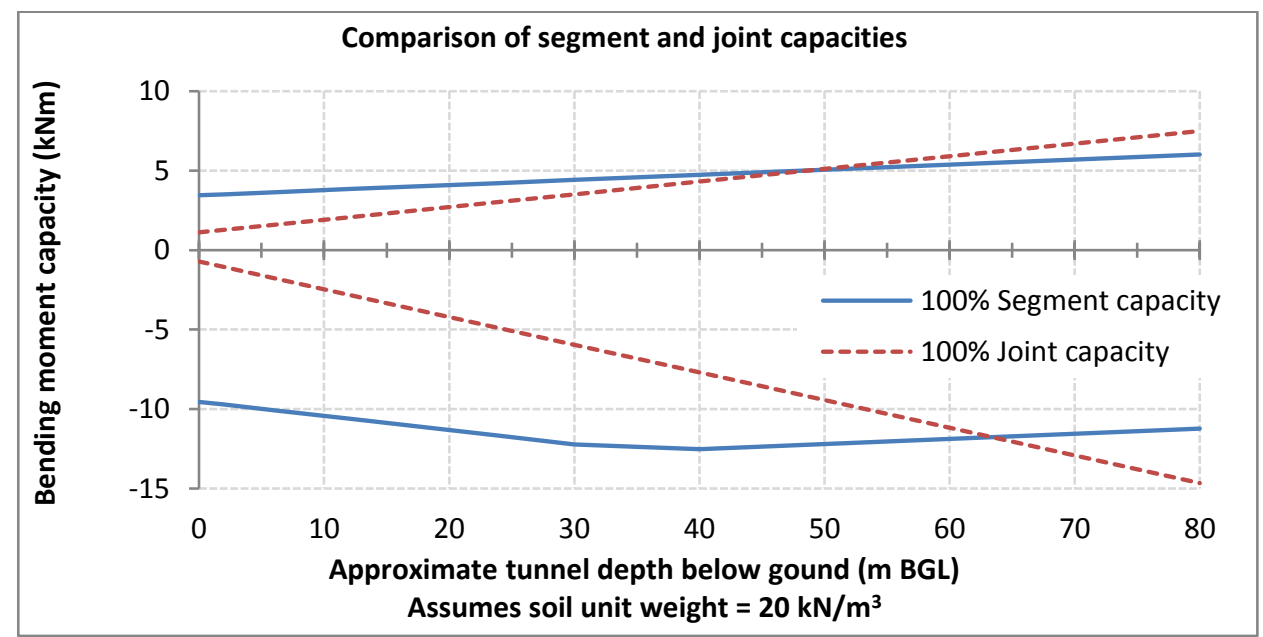

Figure 11. Comparison of segment and joint capacities at different depths.

For a continuous circular ring under any number of equal radial forces equally spaced, standard elastic solutions can be used to calculate the hoop force, bending moments and deflections of the ring (Table 5). By keeping the distortion small such that the tensile stress in the extreme tensile fibre was kept below $40 \%$ of the tensile strength of the $\mathrm{GCl}$, superimposition of the elastic solutions could be used to estimate the ring response under Stage Two loads. For comparison purposes, it was decided to prescribe the same distortion under different hoop forces. The full-ring tests were taken to squatting distortion of up to $0.13 \%$ (Case A in Table 6) and egging distortion of $0.07 \%$ (Case B in Table 6).

The application of load to the segment via a spreader pad was taken into account by superimposing the bending moment distributions from a number of point loads one degree apart over the arc length subtended by the spreader pad. This is illustrated in Figure 12. Figure 13 shows that the bending moment distribution was smoothed over at $90^{\circ}$ when a distributed load was used. 
Table 6 outlines the testing regime. It was considered that the Case A would provide more relevant information to the in-situ tunnels, because excavations adjacent to the existing tunnels would generally cause the existing tunnels to unload.

$\mathrm{P}=$ point load; $\mathrm{E}=$ modulus of elasticity; $\mathrm{A}=$ cross sectional area; $\mathrm{R}=$ radius to the centroid of the cross section; $\mathrm{I}=$ second moment of area of the ring; $\mathrm{s}=\sin \theta ; \mathrm{c}=\cos \theta ; \mathrm{z}=\sin \mathrm{x} ; \mathrm{u}=\cos \mathrm{x} ; \mathrm{k}_{1}=\mathrm{k}_{2}=1\left(\mathrm{k}_{1}\right.$ and $\mathrm{k}_{2}$ are used when correction for hoop or shear stress is necessary, generally for rings with thick walls).

$\mathrm{Max}+\mathrm{M}, \mathrm{Max}-\mathrm{M}$ are maximum positive and negative bending moment around the ring.

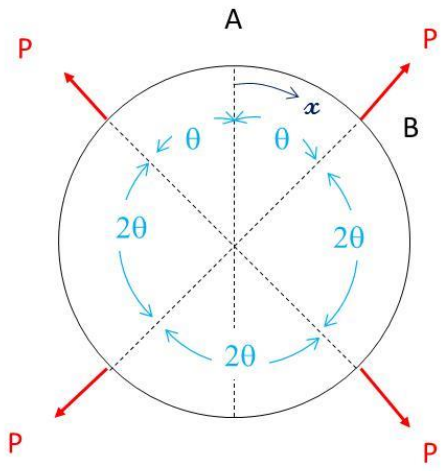

\begin{tabular}{|l|c|}
\hline For $0<\mathrm{x}<\theta$ & $M=\frac{P R\left(u / s-k_{2} / \theta\right)}{2}$ \\
\hline Max $+\mathrm{M}=\mathrm{M}_{\mathrm{A}}$ & $M=\frac{P R\left(1 / s-k_{2} / \theta\right)}{2}$ \\
\hline $\begin{array}{l}\text { Max -M at each load } \\
\text { position }\end{array}$ & $M=\frac{-P R}{2}\left(\frac{k_{2}}{\theta}-\frac{c}{s}\right)$ \\
\hline $\begin{array}{l}\text { Radial displacement } \\
\text { at each load point }= \\
\Delta \mathrm{R}_{\mathrm{B}}\end{array}$ & $\Delta R_{B}=\frac{P R^{3}}{E I}\left(\frac{k_{1}(\theta-s c)}{4 s^{2}}+\frac{k_{2} c}{2 s}-\frac{k_{2}^{2}}{2 \theta}\right)$ \\
\hline $\begin{array}{l}\text { Radial displacement } \\
\text { at } \mathrm{x}=0,2 \theta, \ldots=\Delta \mathrm{R}_{\mathrm{A}}\end{array}$ & $\Delta R_{A}=\frac{-P R^{3}}{E I}\left(\frac{k_{1}(s-\theta c)}{4 s^{2}}-\frac{k_{2}}{2 s}+\frac{k_{2}^{2}}{2 \theta}\right)$ \\
\hline
\end{tabular}

Table 5. Equations for ring under any number of equal radial forces equally spaced (Young and Budynas, 2002).

Axis of symmetry
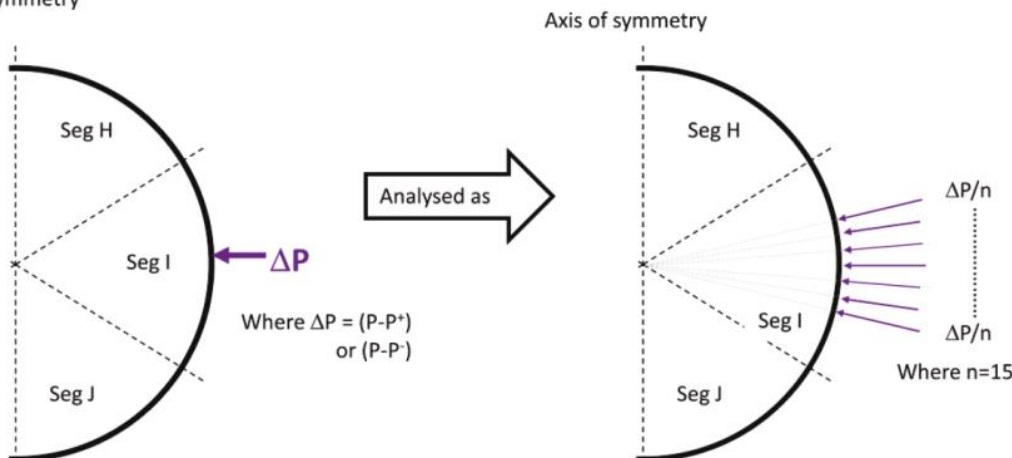

Figure 12. Schematic diagram showing how the loading applied by the spreader pad was modelled. 


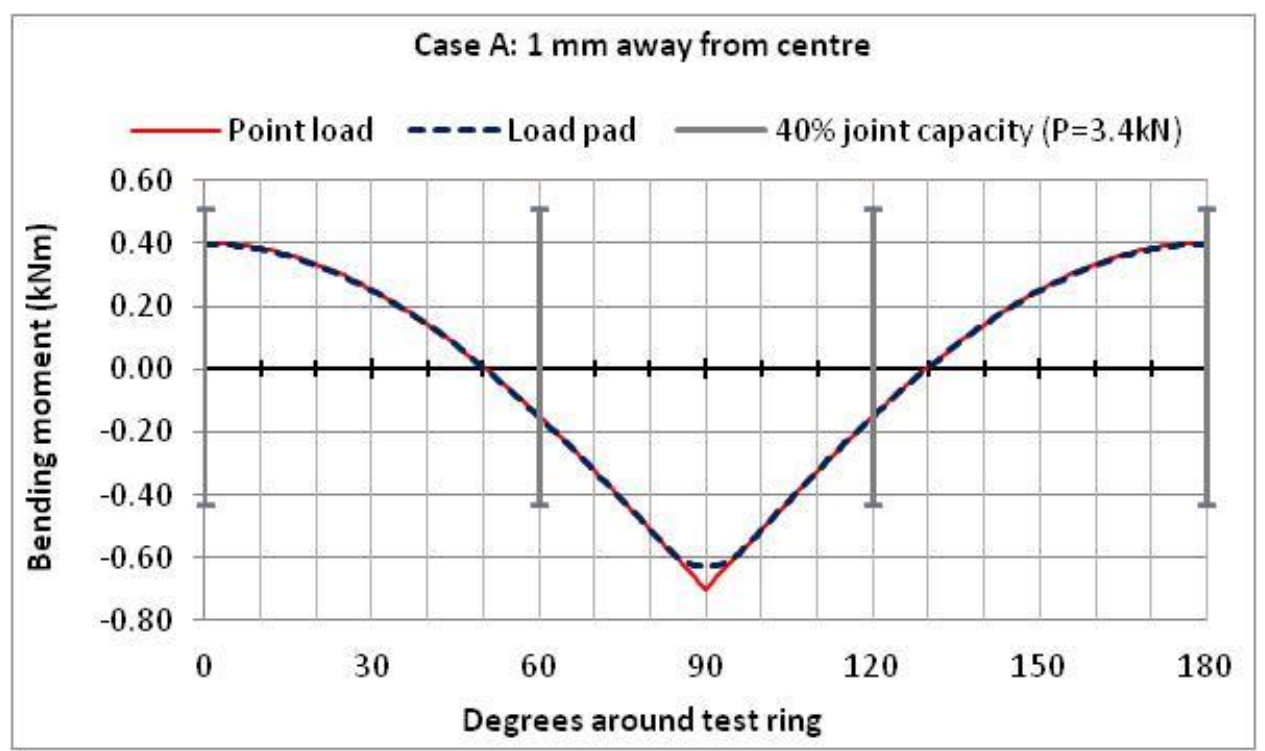

Figure 13. Comparison of bending moment distributions.

\begin{tabular}{|c|c|c|c|c|c|c|c|c|c|}
\hline \multirow{3}{*}{$\begin{array}{l}\text { Stage One } \\
\text { actuator } \\
\text { load, } \mathrm{P}(\mathrm{kN})\end{array}$} & \multirow{3}{*}{$\begin{array}{l}\text { Approx } \\
\text { depth below } \\
\text { ground (m) }\end{array}$} & \multicolumn{8}{|c|}{ Stage Two displacement at axis (mm) } \\
\hline & & \multicolumn{2}{|c|}{ Bolt $7.5 \mathrm{kN}$} & \multicolumn{2}{|c|}{ Bolt $5 \mathrm{kN}$} & \multicolumn{2}{|c|}{ Bolt $10 \mathrm{kN}$} & \multicolumn{2}{|c|}{$\begin{array}{l}\text { Bolt } 5 \mathrm{kN} \\
\text { Grommet }\end{array}$} \\
\hline & & Case A & Case B & Case A & Case B & Case A & Case B & Case A & Case B \\
\hline 3.4 & 2.0 & 1.0 & 1.0 & 1.0 & 1.0 & 1.0 & 1.0 & 1.0 & 1.0 \\
\hline 10.0 & 6.0 & 2.0 & 1.0 & 2.0 & 1.0 & 2.0 & 1.0 & 2.0 & 1.0 \\
\hline 20.0 & 12.0 & 2.0 & 1.0 & 2.0 & 1.0 & 2.0 & 1.0 & 2.0 & 1.0 \\
\hline 40.0 & 24.0 & 2.0 & 1.0 & 2.0 & 1.0 & 2.0 & 1.0 & 2.0 & 1.0 \\
\hline
\end{tabular}

\section{Table 6. Loading regime for main series of tests.}

\section{Results and discussions}

\subsection{Level of control achieved}

Figure 14 compares the hoop forces for a continuous ring under uniform loading estimated from equilibrium (represented by lines) with the hoop forces for the segmental test ring calculated using strain measurements (represented by markers) when the ring was under Stage One loads. The hoop forces have been normalised against the average hoop force obtained from equilibrium to facilitate comparison. The differences between the two could be a result of errors in the strain gauge measurements or the assumed cross sectional area and elastic modulus. Overall, Figure 14 provides confidence that the measured strains and the assumed GCl elastic modulus of $100 \mathrm{GPa}$ are reasonable. Adopting a lower modulus would result in lower forces being calculated.

In order to avoid the cumulative effect of errors, this paper presents and discusses the difference in measurements between Stage One and Stage Two loading. 


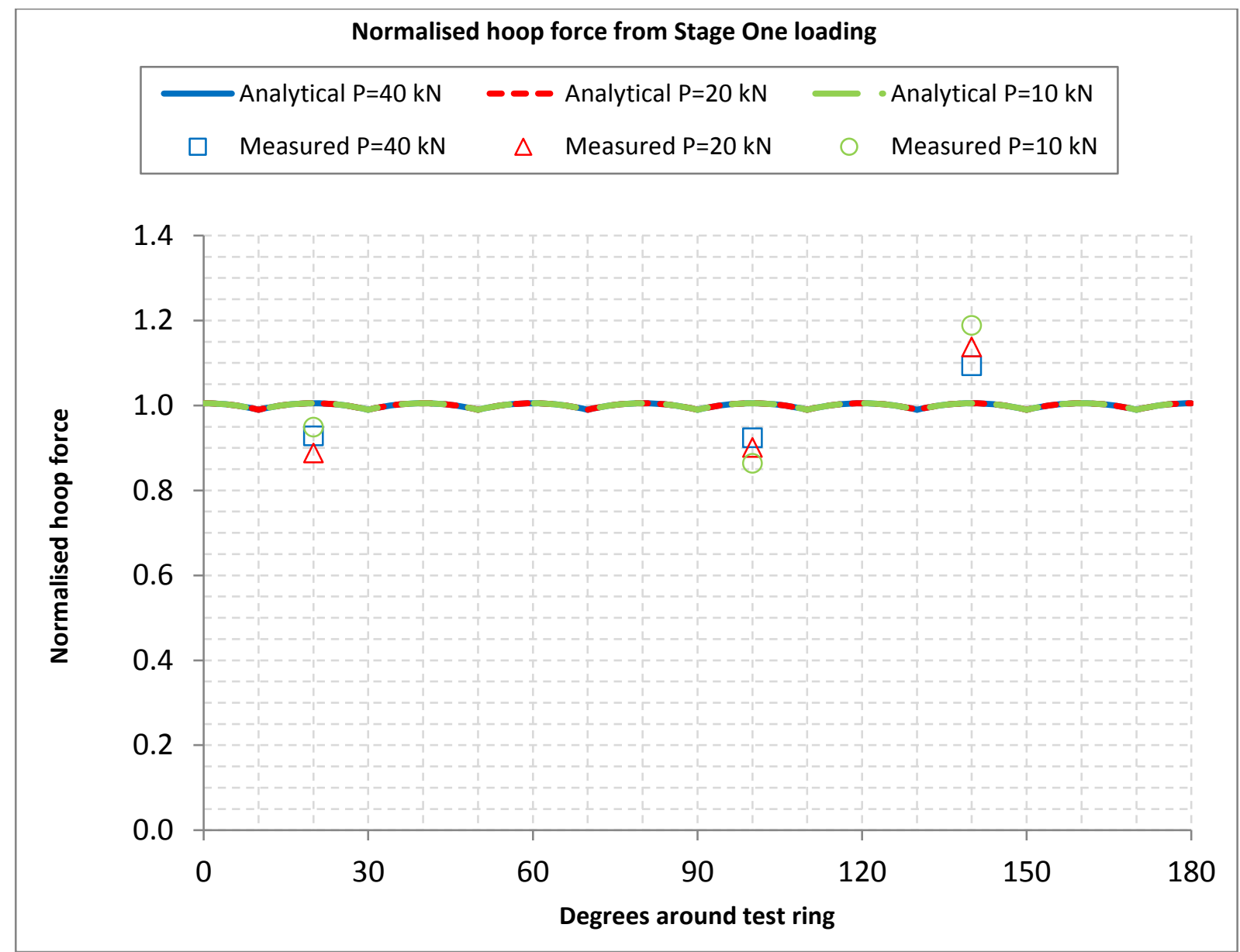

Figure 14. Normalised hoop force from Stage One loading. Hoop forces derived from measured strains are indicated by markers.

Figure 15 shows the measured displacement from zero to 180 degrees (refer to Figure 9), corresponding to the change in radius between Stage One and Stage Two for Case A under different Stage One loads (refer to Table 6). The lines represent the test results where all the bolts were preloaded to $5 \mathrm{kN}$. The markers represent the test results where all the bolts were preloaded to $10 \mathrm{kN}$. The control system worked consistently across all the tests such that practically the same distortion was achieved. 


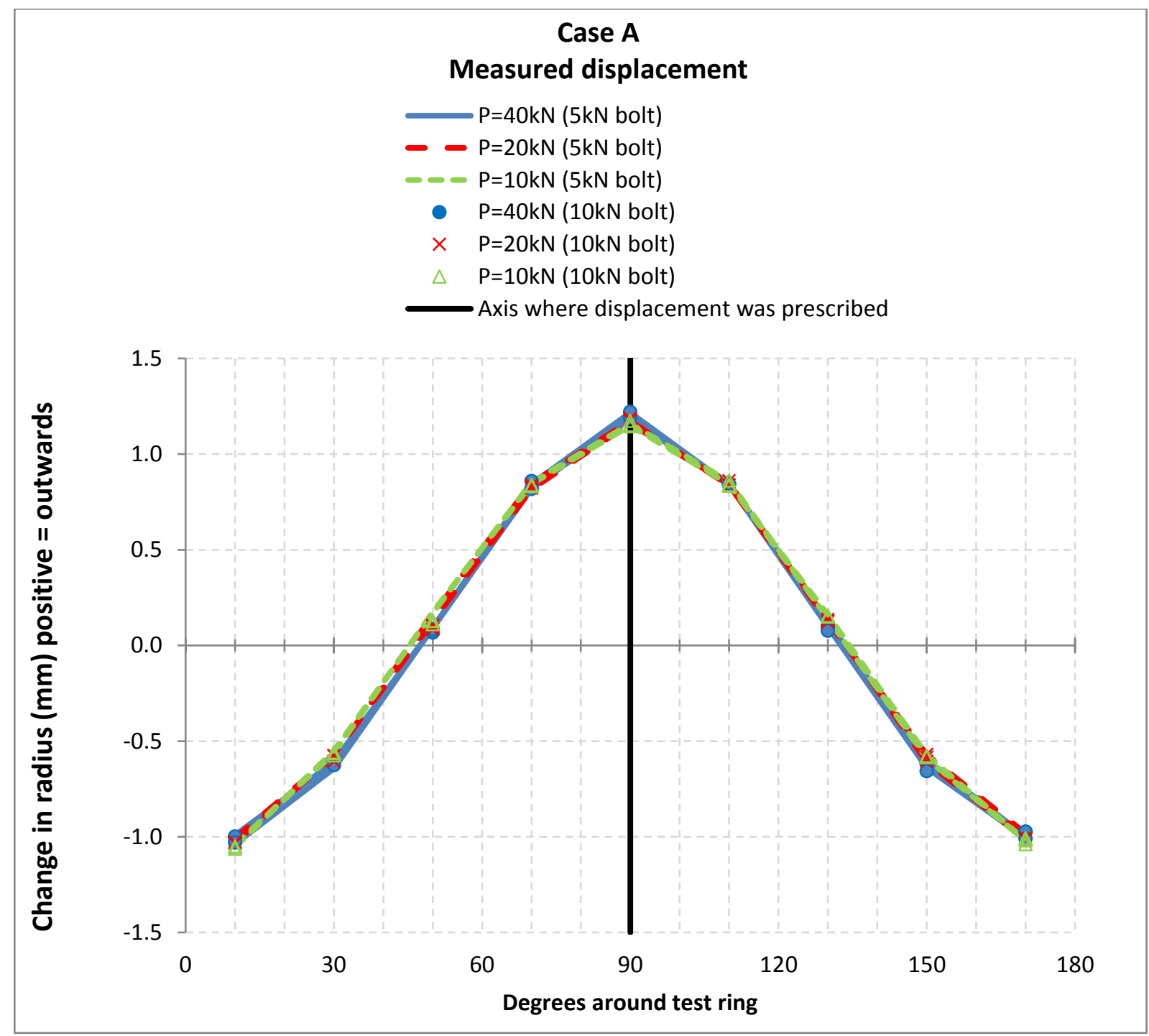

Figure 15. Measured displacement for unloading tests (Case A). Results for two different bolt preloads shown.

\subsection{Measurements of strain and calculations for bending moment}

The bending moment induced in the ring as a result of the imposed distortion was calculated from circumferential strain measurements at four locations around the ring assuming plane sections remained plane (Figure 9). Only the change in strain between Stage One and Stage Two loading was considered. Figure 16 compares the bending moment calculated from strain gauge measurements on segment I and segment G. As seen in Figure 9, these two strain-gauged locations should measure the same changes in strain if the ring was behaving symmetrically. However, Figure 16 shows that the bending moment in segment $G$ was lower than the bending moment in segment I for both Case $A$ and Case B. Replacing the actuators with fixed length reaction bars affected the behaviour of segment $G$. In light of this finding, only the measured response of segments $\mathrm{H}, \mathrm{I}$ and $\mathrm{J}$ was compared against the bending moment distribution of a continuous ring estimated using elastic solutions. 


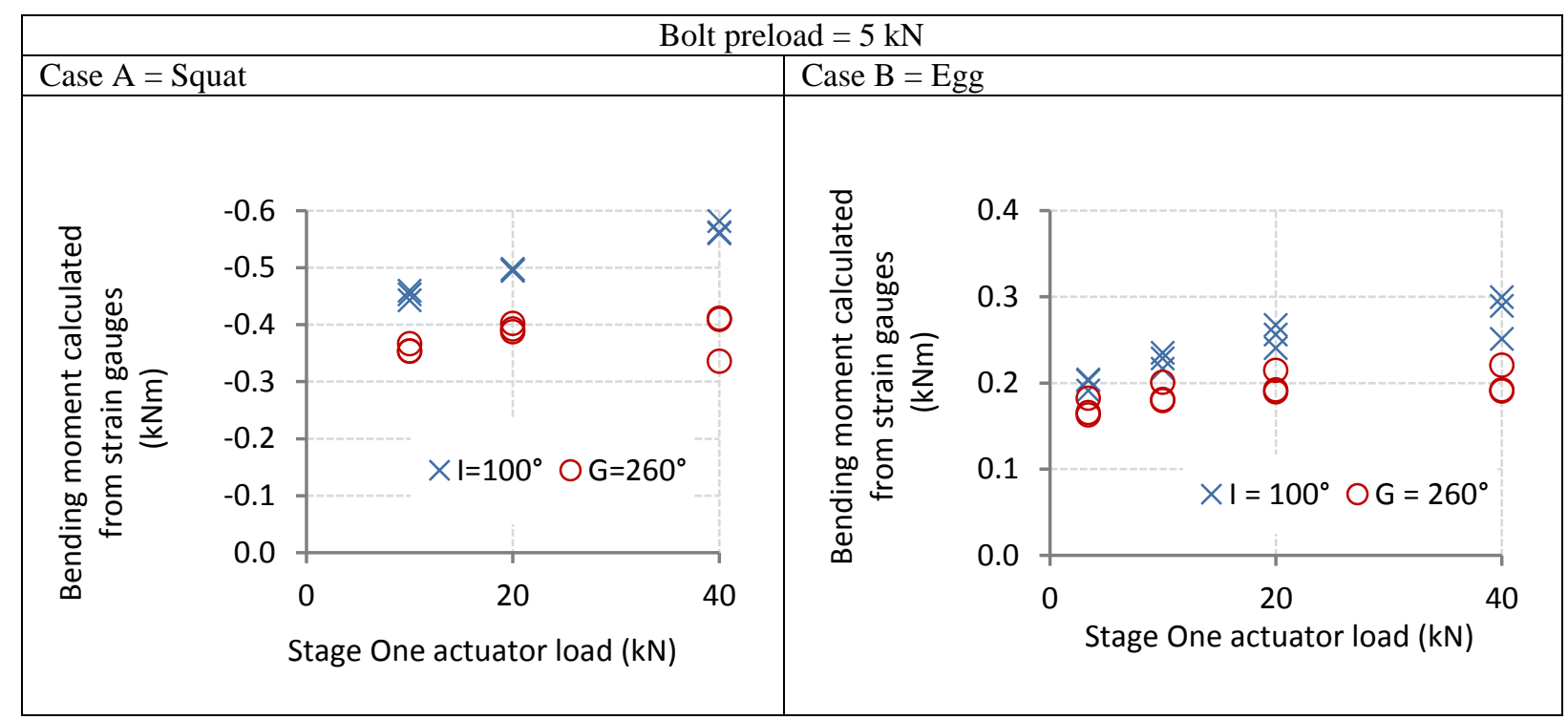

Figure 16. Comparison of bending moments on segment I (100 degrees) and segment G (260 degrees).

The results for Case A with an initial bolt preload of $5 \mathrm{kN}$ are given in Figure 17. The markers give the experimental response calculated from strain gauge measurements and the lines give the bending moment for a continuous ring subjected to the same deformation estimated from elastic solutions. The bending capacities for each joint at $40 \%$ of the estimated value are included in Figure 17. 


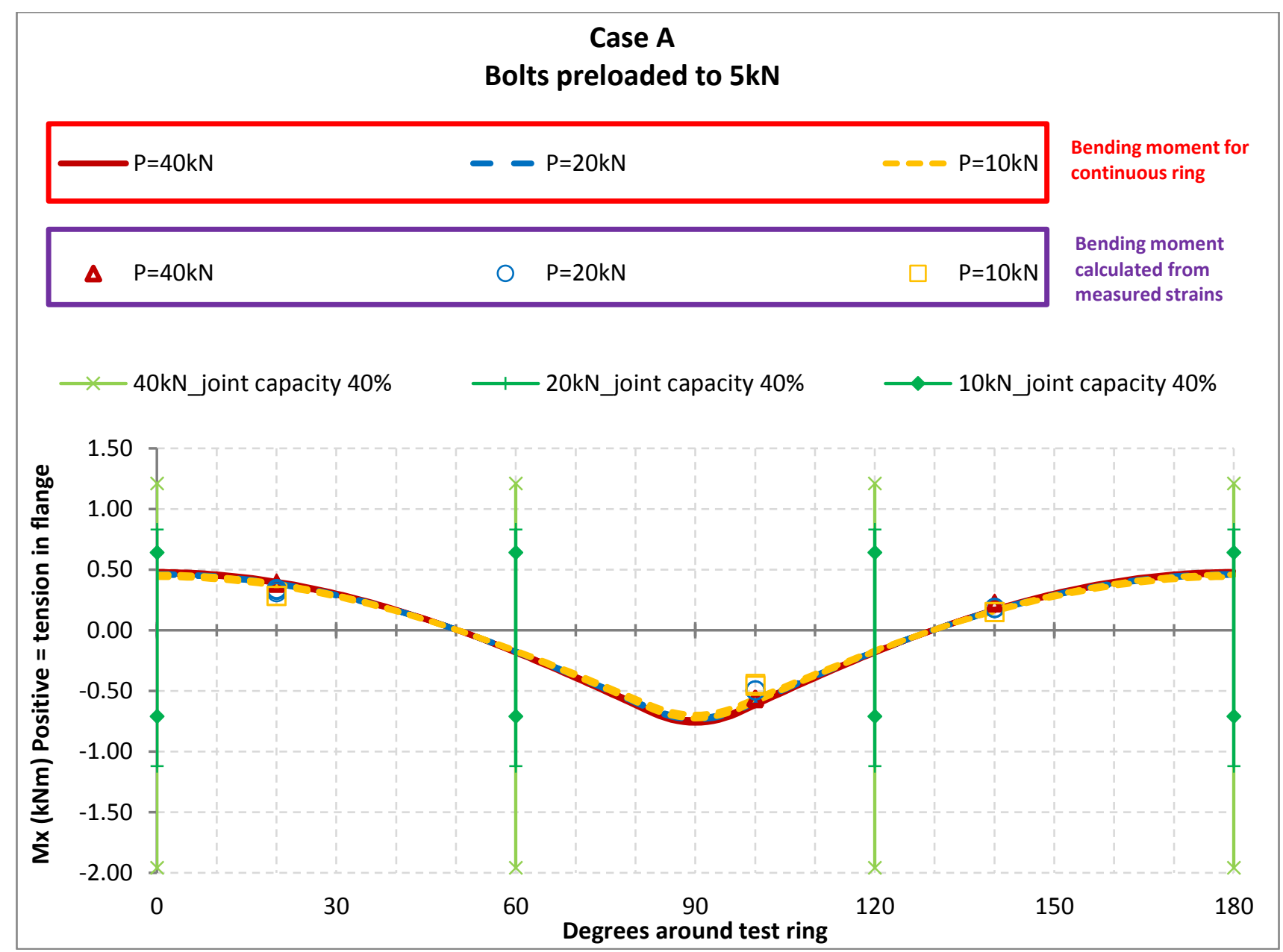

Figure 17. Case A. Bending moment calculated from strain measurements compared with analytical predictions based on the deformed shape. Bolt preload $5 \mathrm{kN}$. Joint capacities at $40 \%$ also shown.

When the segmental ring was subjected to high normal loads of approximately $40 \mathrm{kN}$ before distortion, the measured response at the strain-gauged locations gave calculated bending moments that were similar to the moments calculated in a continuous ring. For the cases with lower normal loads of $20 \mathrm{kN}$ and $10 \mathrm{kN}$ prior to distortion, the bending moments calculated from the measured change in strain were slightly lower than the continuous ring bending moment. This same behaviour was observed for different magnitudes of bolt preload, with or without the inclusion of grommets, and for all the tests with Case B loading.

This implies a reduction in the stiffness of the bolted segmental ring at lower hoop forces. This reduction in ring stiffness was due to the presence of joints, because for a continuous ring made from linear elastic material, the stiffness of the ring would be uniform and the bending moments related to an imposed change in radius would be independent of the hoop force. The small imposed displacements were adopted so that the GCI material would respond mainly elastically. This reduction in stiffness happened when the joints were in tension (start to open) and the joint stiffness affected the ring stiffness.

Figure 18 again shows the results given in Figure 17, but includes the bending moments calculated using Morgan's equation based on the measured distortion at 90 degrees. The Muir Wood reduction 
factor was not used. It would appear that Morgan's equation underestimated the bending moment at 90 degrees for the cases with initial normal loads of $40 \mathrm{kN}$.

Another way to show the variation in the stiffness of the bolted segmental ring under different hoop forces was to compare the forces required to deform the ring by the same magnitude under different hoop forces. The stiffer the ring the greater the force required to achieve the prescribed distortion.

Figure 19 shows the change in load required to achieve Case A distortion. As the Stage One loads increased, a greater change in load was needed to achieve the same deformation. At each level of hoop force, three tests were done. The markers on Figure 19 show the results of each test and the lines show the average of the results. The trends given by different initial bolt preloads were very similar. These results provided more evidence that the bolted segmental ring became stiffer as the hoop force increased.

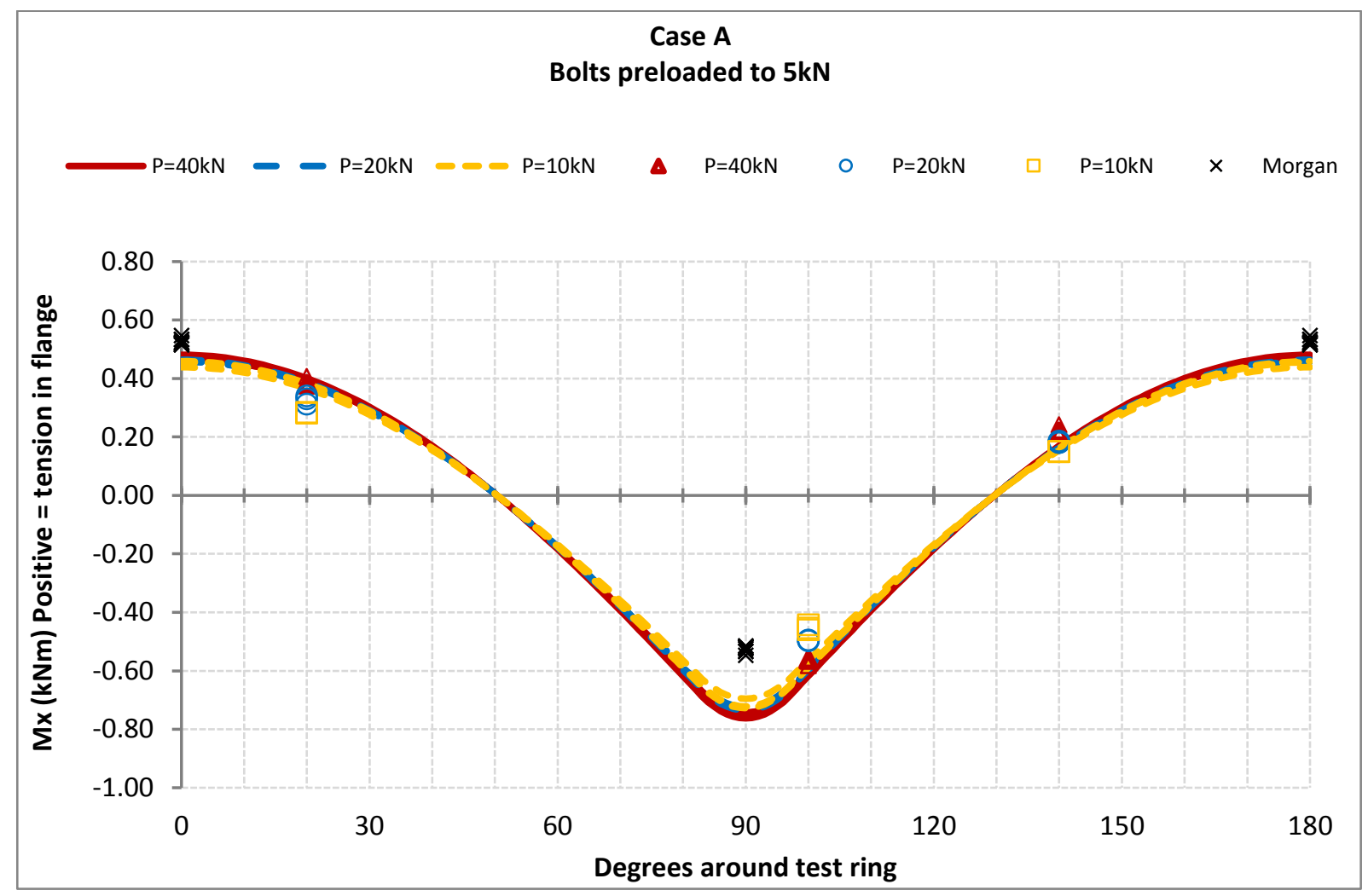

Figure 18. Bending moments calculated from Morgan's Equation compared with bending moments calculated from strain measurements and analytical predictions based on the deformed shape. Case A. 


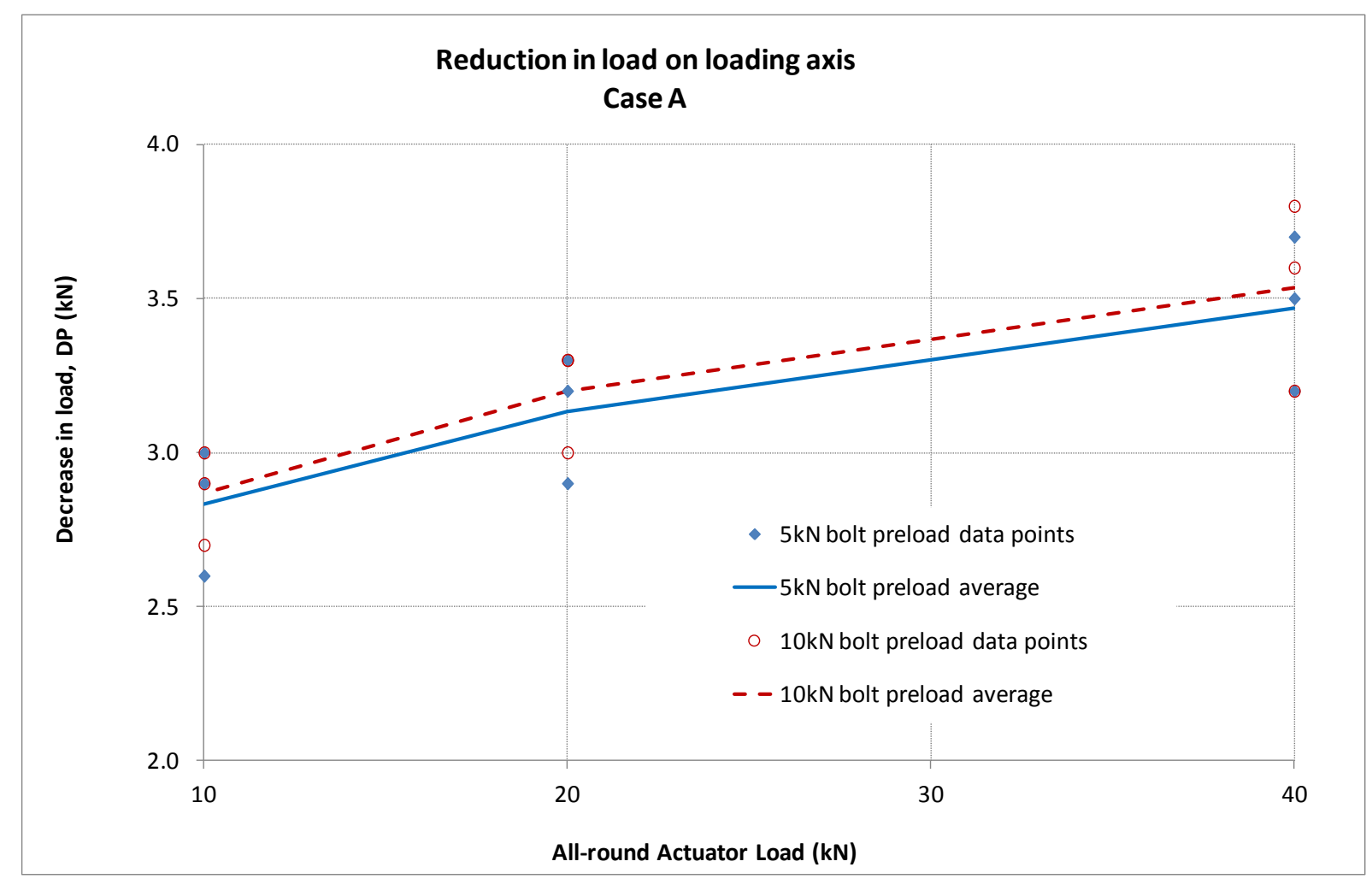

Figure 19. Case A. Changes in actuator load required to deform the ring by the same magnitude.

\subsection{The measured behaviour at the joints}

Figure 20 provides the response of the bolts for Case A loading. The measured changes in bolt load between Stage One and Stage Two for the edge bolts are given. A positive change in load indicates an increase in tension in the bolt. The bolt response under $10 \mathrm{kN}$ and $40 \mathrm{kN}$ Stage One loads are compared.

An increase in Stage One loads resulted in smaller changes in bolt loads upon ring distortion because the joints were largely in compression. When the ring was loaded up to $40 \mathrm{kN}$ prior to distortion the change in bolt loads was negligible. The results do not indicate any clear relationship between the initial preload and the subsequent change in bolt load upon distortion. The inclusion of grommets appears to have lessened the changes in bolt load. Figure 21 shows the reduction in bolt load for several of the instrumented bolts around the ring when grommets were included. The bolts had to be re-tightened several times before a stabilised preload of approximately $5 \mathrm{kN}$ was reached due to creep of the grommets.

The instrumented middle bolts registered negligible changes for both positive and negative moment. Case B loading provided similar results. 


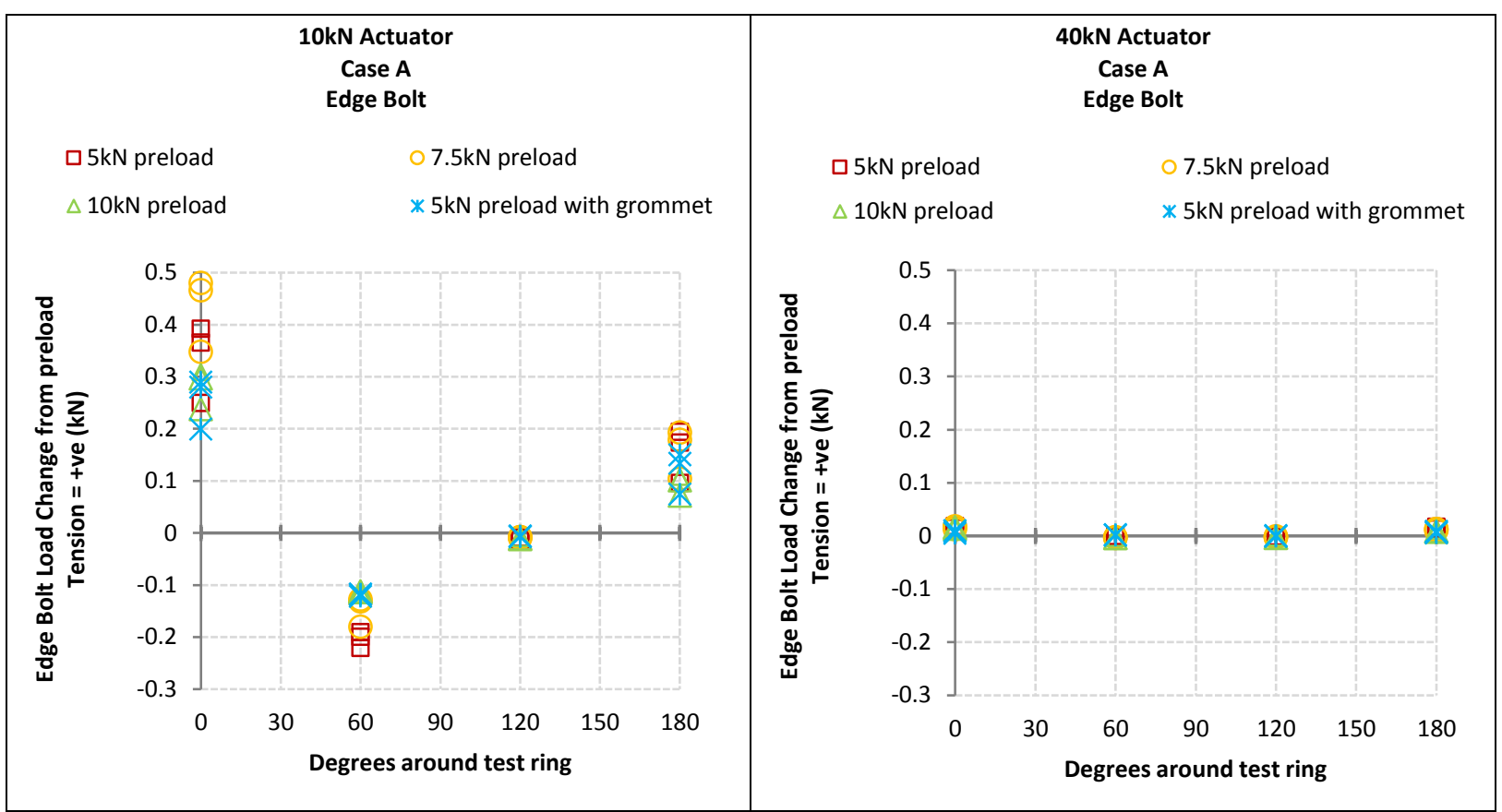

Figure 20. Case A. Change in edge bolt load from Stage One to Stage Two.

Bolts with grommets

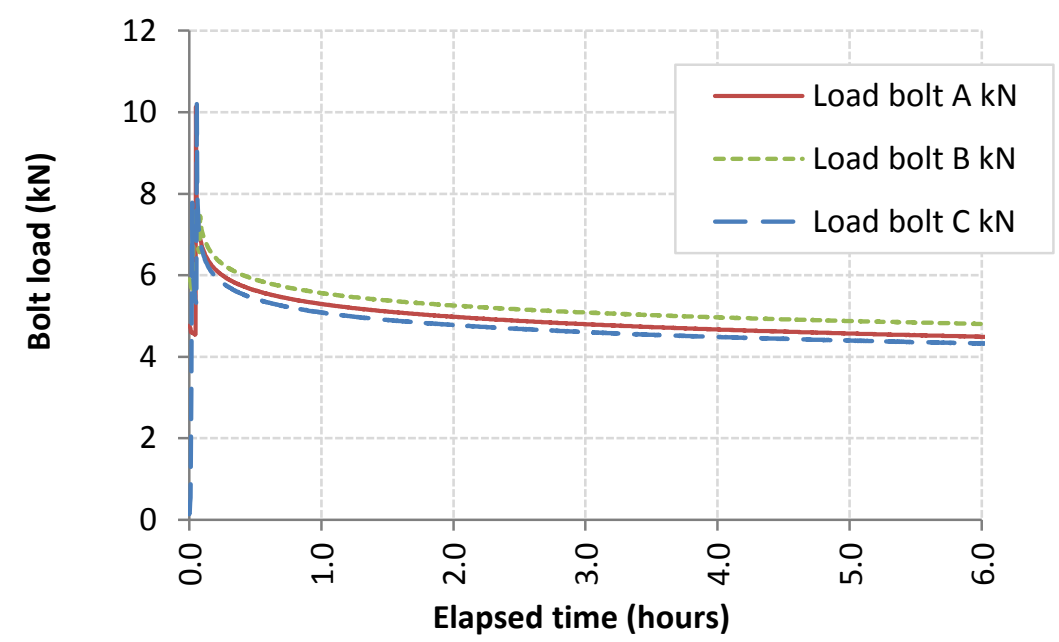

Figure 21. Reduction of bolt preload in all the instrumented bolts when grommets were in place.

Figure 22 presents the results of the joint movements in line with the edge bolt measured along the intrados of the joints for Case A loading after reaching $10 \mathrm{kN}$ and $40 \mathrm{kN}$ Stage One normal loads. A positive change is indicative of the joint opening at that location.

The different initial bolt preload magnitudes, as well as the presence of grommets, had very little effect on the measured joint movement. 


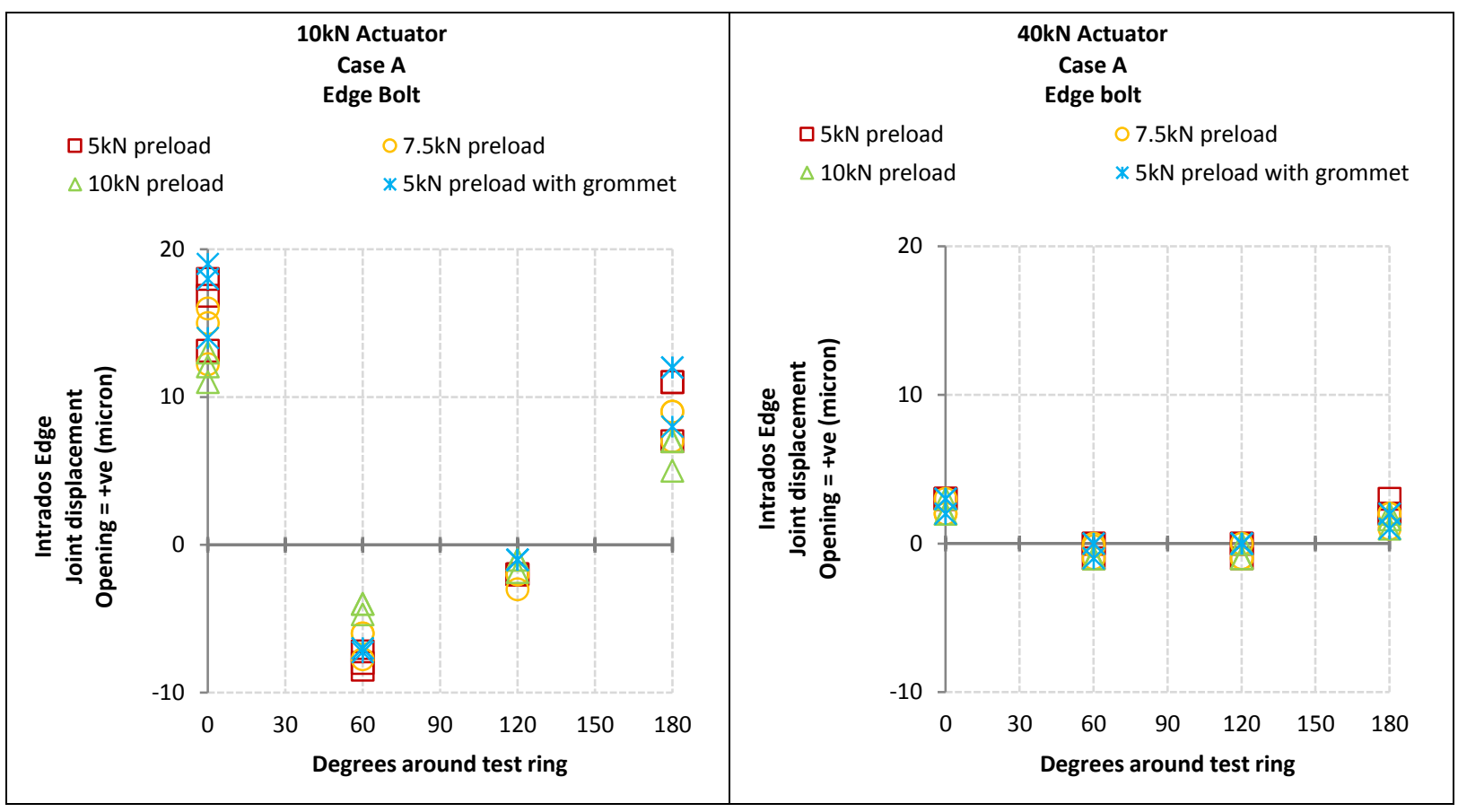

Figure 22. Case A joint movements.

In order to investigate the influence of the initial bolt preload more closely, the measured joint movements for Case A loading where the Stage One load was $10 \mathrm{kN}$ are presented in Figure 23 as distance away from the middle bolt centreline. On the graphs, $x=$ zero is in line with the middle bolt centreline, $x=76$ is in line with the edge bolt centreline, and $x=127$ is in line with the outer edge of the longitudinal flange. The measured change in displacement along the extrados and intrados for the joints at zero and 60 degrees are presented. For case $A$ loading, the joint at $0^{\circ}$ experienced positive bending whilst the joint at $60^{\circ}$ experienced negative bending. Positive displacements are indicative of the joint opening up. The results corresponding to bolt preloads of $5 \mathrm{kN}, 10 \mathrm{kN}$ and $5 \mathrm{kN}$ with grommets are given.

The joint movement along the intrados was up to an order of magnitude greater than the movement along the extrados. The joint movement was negligible at the middle bolt centreline and was largest at the outer edge.

When the preload was $5 \mathrm{kN}$, having the grommets in place made negligible difference to the displacement at the joint. While having a higher preload did result in marginally smaller displacements, the effect is insignificant when compared to the influence of the Stage One loads on joint movement as seen in Figure 22. This suggests that when a segmental ring is under hoop force, the magnitude of preload in the bolts is not a significant factor in determining the behaviour of the joints.

The full set of results for joint displacement is given in $Y u(2014)$. 


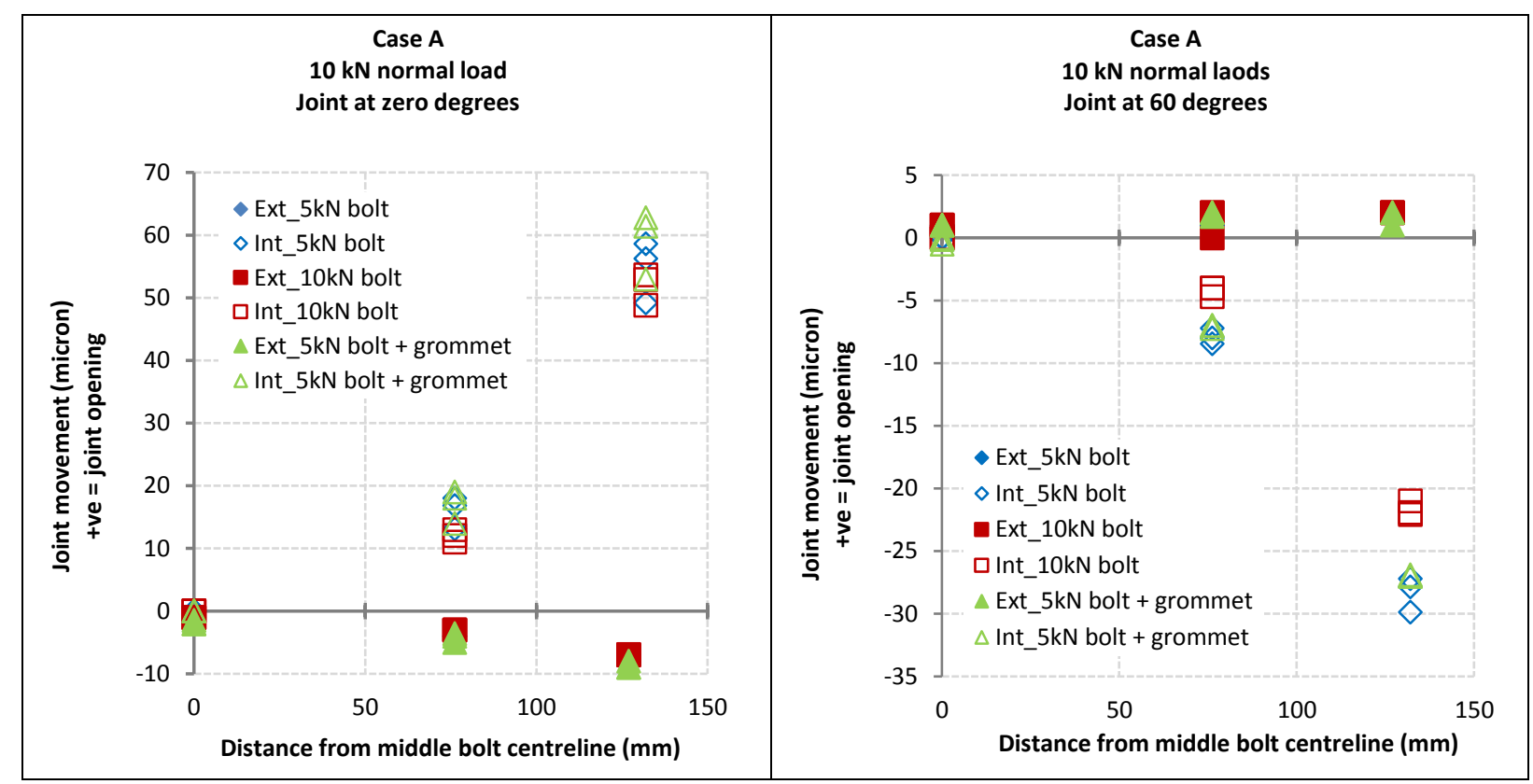

Figure 23. Joint movement along intrados and extrados for different bolt preloads. Normal actuator load $=10 \mathrm{kN}$.

\section{Discussion and conclusions}

In the setup of the experimental investigations, efforts were made to ensure that the half-scale experimental tunnel ring reflected as much as practicable the character of a tunnel ring in-situ. The $\mathrm{GCl}$ mix for the half-scale $\mathrm{GCl}$ segments was specified using the composition obtained from the LU archives. Grommets were specifically produced for the half-scale segment to be included as a test variable. It was considered to be appropriate to use Grade 4.6 mild steel bolts in the experiments.

The decision to apply load with actuators and to eliminate soil from the setup was crucial to the success of the experiments. It would not have been possible to conduct the same number of parametric tests within the time frame if soil was involved. This loading setup allowed very controlled and repeatable tests to be conducted on the half-scale $\mathrm{GCl}$ lining ring. For the first time, the global and local joint response of a bolted segmental GCl lining was studied experimentally and the internal actions relating to a particular deformed shape was measured.

In the laboratory tests, the test ring was subjected to different magnitudes of hoop force before the distortion was imposed with the aim to capture the ring behaviour under a range of overburden pressures.

Because of the possibility to control and measure the loading applied onto the test ring in the laboratory environment, and because the extreme fibre stresses were limited to below $40 \%$ of the ultimate tensile strength of the $\mathrm{GCl}$, it was considered appropriate to compare the results of the segmental full-ring tests with elastic solutions for a continuous ring.

For a typical GCI LU tunnel at $20 \mathrm{~m}$ to $30 \mathrm{~m}$ BGL, the tests conducted under Stage One loads of 40 $\mathrm{kN}$ were the most appropriate. At this level of normal load, the strain measurements from the laboratory tests indicated that the bolted segmental ring behaved as a continuous ring under the imposed diametric distortion of up to $0.13 \%$. The test results did not support using a reduced flexural 
stiffness in the estimation of bending moments in the bolted segmental ring. Negligible joint movement was measured at the middle bolt centreline and the maximum joint movement was measured at the outer edge.

For the small distortions imposed, the presence of compressive hoop force rendered the magnitude of bolt preload insignificant in terms of influencing bolted segmental lining behaviour. Even after the inclusion of grommets, the observed pattern of behaviour did not change. The main effect of including grommets was that the bolt preload reduced with time. In light of this, it is not recommended to disturb the bolts in existing tunnels as mitigating measures, especially since loosening or tightening bolts in the LU tunnels is an extremely time consuming and labour intensive exercise, with the risk of damaging the longitudinal flanges if the bolts were forcibly loosened or over-tightened.

The results from the parametric experiments performed at small deformations described in this paper helped the planning of the very limited number of tests taking the $\mathrm{GCl}$ bolted ring to large deformations, and ultimately, to failure. This work is presented in the paper by Afshan et al (2016).

\section{Acknowledgements}

The authors acknowledge gratefully the funding provided by the EPSRC (Grant number EP/G063486/1), Crossrail Ltd, and Morgan Sindall and the extensive assistance made available by London Underground Ltd. In particular, we would like to thank Mr. Mike Black, Dr. Keith Bowers, Mr. Colin Eddie, Mr. David Harris, Mr. Neil Moss, Dr. Barry New, Mr. Sotiris Psomas, and Mr. Peter Wright for their invaluable advice, encouragement and assistance. The authors must also thank Imperial College research technicians Mr. Duncan Parker, Mr. Steve Ackerley and Mr. Leslie Clark.

\section{References}

Afshan, S., Yu, J., Standing, J.R., Vollum, R., \& Potts, D. (2016) Ultimate capacity of segmented grey cast iron lining subjected to large deformations. Submitted to Tunnelling and Underground Space Technology (May 2016).

Ahn, T. (2011) Thermal and Mechanical Studies of Thin Spray-On Liner (TSL) for Concrete Tunnel Linings. Ph.D Thesis, University of Western Ontario, Canada.

Alhaddad, M., Wilcock, M., Gue, C.Y., Bevan, H., Stent, S, Elshafie, M.Z.E.B., Soga, K., Devriendt, M., Wright, P. and Waterfall, P. (2014) Multi-suite monitoring of an existing cast iron tunnel subjected to tunnelling-induced ground movements. Geotechnical Special Publication. pp. 293-307. ISSN 08950563.

Angus, H.T. (1976) Cast Iron: Physical and engineering properties. Butterworth and Co. Ltd, London, England.

Attewell, P. B. \& El-Naga, N. M. A. (1977) Ground-lining pressure distribution and lining distortion in two tunnels driven through stiff, stony/laminated clay. Ground Engineering, 10 (3), 28-35.

Avgerinos, V. (2014) Numerical investigation of tunnelling beneath existing tunnels. PhD Thesis. Imperial College London. 
Barratt, D. A., O'Reilly, M. P. \& Temporal, J. (1994) London. Long-term measurements of loads on tunnel linings in overconsolidated clay. Tunnelling '94. London, Chapman and Hall. pp. 469-481.

Bilotta, E., Russo, G. and Viggiani, C. (2006) Ground movements and strains in the lining of a tunnel in cohesionless soil. Proc. Int. Symp. Geotechnical Aspects of Underground Construction in Soft Ground, Bakker et al (eds). Taylor Francis Group, London. pp. 705-710.

Blazejowski, M. (2012) Flexural behaviour of steel fibre reinforced concrete tunnel linings. University of Western Ontario. Electronic thesis and dissertation repository, paper 768.

Blom, C.B.M (2003) Design philosophy of concrete linings for tunnels in soft ground. Structural Concrete, Vol. 4, No. 2, pp 89-94.

BS EN 10002-1:2000. Tensile testing of metallic materials. Method of test at ambient temperature. 2001. London, British Standard Institution.

BS EN 1561: 1997. Founding - Grey cast irons. 1997. London, British Standards Institution.

BS EN 1993-1-8:2005. Eurocode 3 - Design of Steel Structures - Part 1-8: Design of Joints. 2006. London, British Standard Institution.

BS EN ISO 6892-1:2009. Metallic materials. Tensile testing. Method of test at ambient temperature. 2009. London, British Standard Institution.

Cooley, P. (1982) Wedge-block tunnels in water supply. Journal of the Institution of Water Engineers and Scientists, 36 (February), 9-29.

Cooling, L. P. \& Ward, W. H. (1953) Measurements of loads and strains in earth supporting structures. Proceedings of the third International Conference on Soil Mechanics and Foundation Engineering. Zurich. pp. 162-166.

Cooper, M. L., Chapman, D. N., Rogers, C. D. F. \& Chan, A. H. C. (2002) Movements in the Piccadilly Line tunnels due to the Heathrow Express construction. Géotechnique, 52 (4), 243-257.

Cooper, M.L. \& Chapman, D.N. (2000) Settlement, rotation and distortion of Piccadilly Line tunnels at Heathrow. In: O. Kusakabe, K. Fujita \& Y. Miyazaki (eds.) Geotechnical Aspects of Underground Construction in Soft Ground, Rotterdam Balkema, pp. 213-218.

Cooper, M.L. (2001) Tunnel-induced ground movements and their effects on existing tunnels and tunnel linings. PhD thesis. The University of Birmingham.

Cooper, M.L., Chapman, D.N., Chan, A.H.C. \& Rogers, C.D.F (2003) Prediction of effects of new tunnelling on existing tunnels. In: Jardine, F.M. (eds) Response of buildings to excavation-induced ground movements. CIRIA SP199, London, pp.233-243.

Copperthwaite W.C. (1906) Tunnel shields and the use of compressed air in subaqueous works. Archibald Constable \& Co Ltd., London.

Craig R.N. and Muir Wood A.M. (1978) A review of tunnel lining practice in the United Kingdom. TRRL Supplementary Report 335, Transport Road Research Laboratory. 
Davies, H.R. \&Bowers, K.H. (1996) Design and installation of special tunnel rings to monitor long term ground loading. In: Mair, R.J., Taylor, R.N. (eds) Geotechnical aspects of underground construction in soft ground: Proceedings of the International Symposium. A A Balkema Publishers, pp. 257-261.

Fallon, M.J. (1998) Evaluation of the Properties and Integrity of Six Tunnel Segments and a Bridge Support Section used by London Underground. The Castings Development Centre. March 1998.

Gilbert, G. N. J. (1977) Engineering Data on Grey Cast Iron - SI Units. Alvechurch, BCIRA. Report number: Report 1285.

Gue C.Y., Wilcock, M.M., Alhaddad, M.M., Elshafie, M.Z.E.B, Soga, K. and Mair, R.J. (2014) Monitoring the effects of tunnelling under an existing tunnel - fibre optics. Proc. Geotechnical aspects of Underground construction in Soft Ground (Eds YooC., Park, S-W., Kim, B. \& Ban, H.CRC PressTaylor and Francis Group. pp. 357-361.

Hewitt B.H.M. and Johannesson S. (1922) Shield and compressed air tunnelling. McGraw, London.

Kimmance, J. P., Lawrence, S., Hassan, O., Purchase, N. J. \& Tollinger, G. (1996) Observations of deformations created in existing tunnels by adjacent and cross cutting excavations. In: Mair, R. J. \& Taylor, R. N. (eds.) Geotechnical Aspects of Underground Construction in Soft Ground: Proceedings of the International Symposium. Taylor Francis Group. Rotterdam. pp. 707-712.

Leung, K. (1967) Bolting Stresses in Tunnel Segments. MSc. University of Glasgow.

London Underground. (2014) Civil Engineering - Deep Tube Tunnels and Shafts. Standard. A3. Report number: S1055.

Mashimo, H., Isago, N., Shiroma, H. and Baba, K. (2001) Experimental study on static behaviour of road tunnel lining. Proc. Modern Tunnelling Science and Technology, Vol. 1, pp 451-456.

Mashimo, H., Isago, N., Yoshinaga, S., Shiroma, H. and Baba, K. (2002) Experimental investigation on load-carrying capacity of concrete tunnel lining. Proc. 28th ITA General Assembly and World Tunnel Congress AITES-ITA DOWNUNDER.

Morgan, H. D. (1961) A Contribution to the Analysis of Stress in a Circular Tunnel. Géotechnique. Volume 11, Issue 1, pp 37-46.

Moss N.A. and Bowers K.H. (2006) The effect of new tunnel construction under existing metro tunnels. Proc. Int. Symp. Geotechnical Aspects of Underground Construction in Soft Ground, Bakker et al. (eds). Taylor Francis Group, London, pp. 151-157.

Muir Wood, A.M. (1975) The circular tunnel in elastic ground, Géotechnique, Volume 25, Issue 1, pp 115-27.

Nyren, R. J. (1998) Field measurements above twin tunnels in London Clay. PhD. Imperial College, University of London.

Okano, N. (2007) Development of a testing machine with a large tunnel lining model. Railway Technology Avalanche, No. 19, September, p 2. 
Rapp, G. M. \& Baker, A. H. (1936) The measurement of soil pressures on the lining of the Midtown Hudson Tunnel. Proceedings of the 1st International Conference on Soil Mechanics and Foundation Engineering. Harvard. pp. 150-156.

Russell Ductile Castings (2010) Test Certificate No. 36959. Dated 17 March 2010.

Skempton, A. W. (1943) Discussion. Tunnel linings with special reference to a new form of reinforced concrete lining. Proceedings of the Institution of Civil Engineers, 20 (5), 53-56.

Smith Osborne, R. (1970) Discussion: The Victoria Line. Proceedings of the Institution of Civil Engineers., Supplement xiii (Paper 7270S), 319-322.

Standing, J. R. \& Selman, R. (2001) The response to tunnelling of existing tunnels at Waterloo and Westminster. In: Burland, J. B., Standing, J. R. \& Jardine, F. M. (eds.) Building response to tunnelling. Case studies from the Jubilee Line Extension, Case studies. London, CIRIA and Thomas Telford, London. pp. 509-564.

Standing, J.R. \& Lau, C. (2016) Small-scale model for investigation tunnel lining deformations. Submitted to Tunnelling and Underground Space Technology (October 2015).

Standing, J.R., Potts, D., Vollum, R., Burland, J., Tsiampousi, A., Afshan, S., Yu, J., Wan, M., \& Avgerinos, V. (2015) Investigating the effect of tunnelling on existing tunnels. Proc. Underground Design and Construction Tunnelling Conference. IOM3. Hong Kong.

Sutherland, H. B. (1955) Discussions. Conference on the Correlation between Calculated and Observed Stresses and Displacements in Structures. London, Institution of Civil Engineers. pp. 370486.

Tattersall, F., Wakeling, T. R. M. \& Ward, W. H. (1955) Investigations into the design of pressure tunnels in London Clay. Proceedings of the Institution of Civil Engineers, 4 (4), 400-455.

Thomas, H. S. H. (1976) Structural performance of a temporary tunnel lined with spheroidal graphite cast iron. Proceedings of the Institution of Civil Engineers., 61 (2), 89-108.

Thomas, H. S. H. (1977) Measuring the structural performance of cast iron tunnel linings in the laboratory. Ground Engineering, 10 (5), 29-36.

Thomas, H. S. H. (1983) Observations on the behaviour of a pilot tunnel in London clay as the main tunnel was driven. Proceedings of the Institution of Civil Engineers., 74 (1), 15-24.

Tube Lines. (2006) Strain Measurement Report. Deep Tube Tunnel Knowledge and Inspection Programme Annual Works Plan 2. 2. London, Tube Lines. Report number: Document No. TLL-L001N416-DTAAWP2-TUN-RPT-00015.

Tube Lines. (2007) Cast Iron Tunnels and Shafts Report. Deep Tube Tunnel Knowledge and Inspection Programme Annual Works Plan 2. Document No. TLL-L001-N416-DTAAWP2-TUN-RPT00002. Revision 4.0 dated 03/03/2007. 
Tube Lines. (2008) Cast Iron Coring Report. Deep Tube Tunnel Knowledge and Inspection Programme Annual Work Plan 2. Revision 4 issued on 22/09/2008. Document No. TLL-L001-N416DTAAWP2-TUN-RPT-00019.

Underground Professional Services. (2009) Drawing number UnPS/ICR/GN/D/0004 revision C1. Half size model of 12'6" cast iron tunnel lining.

Ward, W. H. \& Chaplin, T. K. (1957) Existing stresses in several old London Underground tunnels. Proceedings of the 4th International Conference on Soil Mechanics and Foundation Engineering. London. pp. 256-259.

Ward, W. H. \& Thomas, H. S. H. (1965) The development of earth loading and deformation in tunnel linings in London Clay. Proceedings of the 6th International Conference on Soil Mechanics and Foundation Engineering. Montreal, University of Toronto Press. pp. 432-436.

Young, W. C. \& Budynas, R. G. (2002) Curved Beams. In: Roark's Formulas for Stress and Strains. 7th edition. New York, McGraw Hill Companies, Inc. pp. 267-380.

$\mathrm{Yu}$, J. (2014) Assessing ground interaction effects and potential damage on existing tunnels before and after new excavation works. PhD Thesis. Imperial College London.

Yu, J., Standing, J.R., Vollum, R., \& Potts, D. (2014) Tunnelling Induced Strains and Deformations at Central Line. In: Black, Lawrence and Dodge eds. Crossrail Project: Infrastructure Design and Construction, London, ICE, pp. 499-518.

Yu, J., Tsiampousi, A., Standing, J.R., Vollum, R., \& Potts, D. (2015) A laboratory and finite element study on bolted grey cast iron joint behaviour. Submitted to Tunnelling and Underground Space Technology.

\section{Appendix A}

The bending moment capacity of the joint was estimated based on a simplified analysis of the flexural capacity of the longitudinal flange. Thomas (1977) found that when a pair of segments were bolted together at the longitudinal joint and tested such that there was positive bending at the joint, i.e., tension on the intrados, the middle bolt on the longitudinal flange carried substantially less load than the two outside bolts when the segment was subjected to bending. Keeping this in mind, only the contribution from the two edge bolts were taken into account when estimating the positive bending capacity of the joint.

The calculations are outlined in Table 7. The schematic view in the table shows the longitudinal flange with three bolt holes in line. During positive bending, the area $A$ is assumed to be effective in transferring tension from the bolt onto the circumferential flange. The triangular area $A$ of the flange was assumed to deform as a cantilever in double curvature and the maximum bolt load was estimated from the flexural strength of the cantilever (Part 1, Table 7). The bending moment capacity of the joint was then estimated by multiplying the maximum bolt load with the respective lever arms for positive bending or negative bending of the joint. 
The decision to assume double curvature was based on a review of test data from Thomas (1977) who measured the increase in bolt load above initial preload with increasing bending moment in his two segment test using full-scale $\mathrm{GCl}$ segments. Assuming double curvature bending and the contribution from the two edge bolts, the positive bending capacity of the joint was calculated to be $1.12 \mathrm{kNm}$. Recent experiments carried out by Yu et al (2015) have shown that all three bolts along the longitudinal flange contribute equally in negative bending. Therefore the negative bending capacity was estimated to be $0.72 \mathrm{kNm}$.

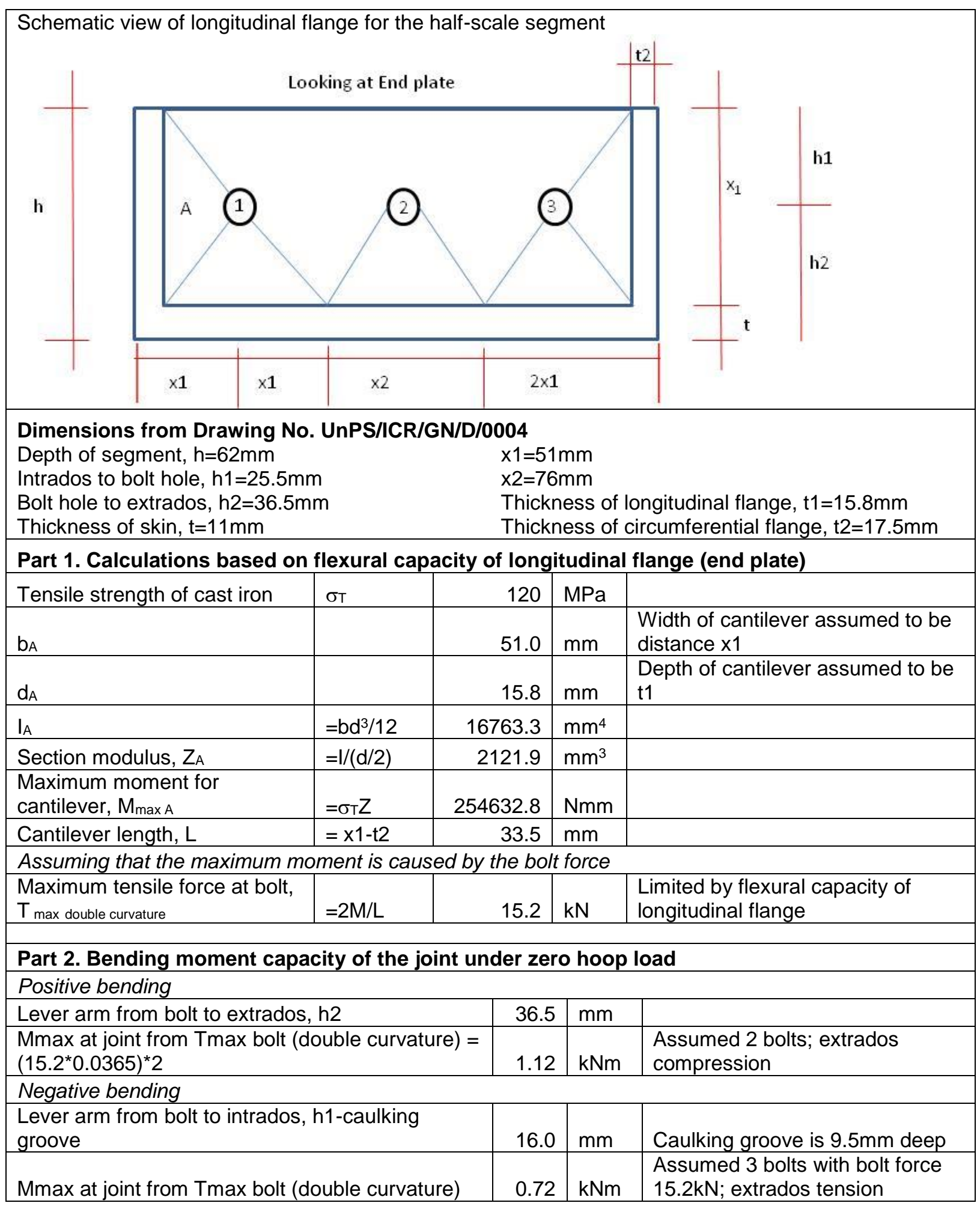


Part 3. Additional bending moment capacity of the joint with hoop load

Compressive hoop force, $\mathrm{N}$

Bending moment $=\mathrm{Ne}$, where

$\mathrm{e}=16.5 \mathrm{~mm}$ for positive bending (centroidal axis to extrados)

$\mathrm{e}=36.0 \mathrm{~mm}$ for negative bending (centroidal axis to caulking groove)

Table 7. Initial estimate of joint bending capacity. 